Macroprudential Stress Testing of Credit Risk: A Practical Approach for Policy Makers

Daniel Buncic, Martin Melecky

September 2011 Discussion Paper no. 2011-39 


$\begin{array}{ll}\text { Editor: } & \text { Martina Flockerzi } \\ & \text { University of St. Gallen } \\ & \text { School of Economics and Political Science } \\ & \text { Department of Economics } \\ & \text { Varnbüelstrasse 19 } \\ & \text { CH-9000 St. Gallen } \\ & \text { Phone +41 71 224 23 25 } \\ & \text { Fax } \quad+41712243135 \\ & \text { Email seps@unisg.ch } \\ & \text { School of Economics and Political Science } \\ & \text { Department of Economics } \\ & \text { University of St. Gallen } \\ & \text { Varnbüelstrasse 19 } \\ \text { Publisher: } & \text { CH-9000 St. Gallen } \\ & \text { Phone +41 71 224 23 25 } \\ & \text { Fax +41 71 224 31 35 } \\ & \text { http://www.seps.unisg.ch }\end{array}$




\title{
Macroprudential Stress Testing of Credit Risk: A Practical Approach for Policy Makers ${ }^{1}$
}

\author{
Daniel Buncic, Martin Melecky
}

Author's address:

\author{
Daniel Buncic \\ Institute of Mathematics and Statistics \\ Bodanstrasse 6 \\ $\mathrm{CH}-9000$ St. Gallen \\ Phone +41712604 \\ Fax $\quad+41712894$ \\ Email_daniel.buncic@unisg.ch \\ Website www.danielbuncic.com \\ Martin Melecky \\ Financial \& Private Sector Development \\ The World Bank \\ Washington DC \\ Mail stop H4-410 \\ Phone +12024731924 \\ Email mmelecky@worldbank.org
}

\footnotetext{
${ }^{1}$ We thank Martin Cihak, Joaquin Gutierrez and Maria Soledad Martinez Peria for comments on an earlier draft of this paper. The views and opinions expressed in the paper are those of the authors and do not reflect those of the World Bank or its Executive Directors.
} 


\begin{abstract}
Drawing on the lessons from the global financial crisis and especially from its impact on the banking systems of Eastern Europe, the paper proposes a new practical approach to macroprudential stress testing. The proposed approach incorporates: (i) macroeconomic stress scenarios generated from both a country specific statistical model and historical crosscountry crises experience; (ii) indirect credit risk due to foreign currency exposures of unhedged borrowers; (iii) varying underwriting practices across banks and their asset classes based on their relative aggressiveness of lending; (iv) higher correlations between the probability of default and the loss given default during stress periods; ( $v$ ) a negative effect of lending concentration and residual loan maturity on unexpected losses; and (vi) the use of an economic risk weighted capital adequacy ratio as the relevant outcome indicator to measure the resilience of banks to materialising credit risk. We apply the proposed approach to a set of Eastern European banks and discuss the results.
\end{abstract}

\title{
Keywords
}

Supervision, Stress Test, Individual Bank Data, Eastern Europe.

\section{JEL Classification}

G28, E58, G21. 


\section{Introduction}

The financial crisis has revealed the need for better macroprudential oversight and a more appropriate policy response. It is widely accepted in the literature that the contribution of financial sector stability and its development are vital for economic growth. Any disruptions to the functioning of the financial sector due to excessive exposures to risk and financial deleveraging are known to be detrimental to economic growth, resulting in reduced incomes, greater income inequality, reduced employment levels and social unrest. With every financial crisis or disruption of the functioning of the financial system, confidence in such a system and its potential contribution to economic growth can decline. Vigilant prudential monitoring of financial systems that supports informed and timely policy decisions on supervisory interventions and appropriate changes in financial regulation is therefore an important task of any supervisory institution.

The main tool of macroprudential monitoring is regular stress testing of the financial system. Stress testing is particularly important during periods of benign conditions when the memory of past detrimental events has faded out. The development, institutionalisation and regular application of stress tests forces financial sector specialists, supervisors and policy makers not to forget past crises and thus enhances macroprudential monitoring and crisis preparedness. Despite the widely recognised importance of conducting stress tests, there appears to be a consensus among macroprudential practitioners that stress tests were not informative enough and did not enforce an adequate policy response prior to the global financial crisis (Haldane, 2009; Čihák, 2007; Turner, 2009; de Larosiére, 2009; Sorge, 2004; Galati and Moessner, 2011). This partial failure of stress tests has lead to the development of a new generation of stress testing models based on the lessons learned from the recent crisis (Foglia, 2009; Swinburne, 2007; Breuer, Jandacka, Rheinberger and 
Summer, 2009).

It is important that both key macroprudential and microprudential aspects are appropriately incorporated when constructing macroprudential stress tests. This being said, it has to be emphasised that macroprudential stress tests need to capture different features than standard microprudential stress tests which are commonly applied to individual banks. The reason for this is that macroprudential stress tests need to be explicitly linked to changing macroeconomic conditions. They also need to be tractable and easily understood by policy makers who have to be able to detect the main risks to the banking system at various levels of aggregation, i.e., at the individual bank level, the bank group level and at the system level, in order to serve as a useful tool for policy analysis and as a unifying framework for policy debate.

Recent history has shown that credit risk is at the heart of solvency problems in the banking sector, manifesting itself largely through balance sheet and cash flow solvency problems of banks. ${ }^{1}$ The objective of this study is to design a credit risk stress testing methodology that can be used for macroprudential monitoring and which reflects on the impact of the global financial crisis on the banking systems of Eastern Europe. Eastern Europe was arguably one of the most heavily affected regions by the spillovers from the global financial crisis (World Bank, 2008).

The proposed stress testing methodology produces outcome indicators that account for systemic as well as idiosyncratic economic risks at the level of an individual bank and the banking sector. This is accomplished by integrating the following components into the proposed stress testing methodology. First, we explicitly link non-performing loans

\footnotetext{
${ }^{1}$ This should not, however, diminish the importance of appropriately integrating stress tests for any of the idiosyncratic risks that banks face in their operations in addition to credit risks. In that regard, the interplay between credit risk and liquidity risk is especially important.
} 
to changing macroeconomic conditions by estimating the elasticities of non-performing loans to a set of key macroeconomic variables. This captures the systemic transmission from the macroeconomy to the performance of bank credit portfolios. Second, we construct macroeconomic Stress scenarios in two different ways, where one is based on a country specific macroeconomic model, and the other is computed from historical macroeconomic data of countries that have experienced financial crises in the past. Third, we allow the sensitivity of credit risk to changing macroeconomic conditions to increase during crisis times. Fourth, we approximate the underwriting standards of individual banks by the aggressiveness of their lending in the individual asset classes at the peak of the most recent credit cycle or during the most recent credit boom period, and penalise banks that grew their asset class faster than the average bank. Fifth, we employ a bank and asset class specific penalty linked to the share of unhedged foreign currency lending. Sixth, we build on the results of the study by Moody's (2010) and allow the correlation between the probability of default and the loss given default to increase in times of stress. Seventh, we account for a bank's lending concentration within individual asset classes, and the extent of the performed maturity transformation in the computation of the bank and asset class specific capital charges. These seven components are combined to construct a more relevant outcome indicator for measuring bank resilience to macroeconomic as well as bank specific shocks.

Some of the early stress testing approaches which were intended for use by policy makers, as, for example, that of Čihák (2007), are fundamentally financial simulations where no formal links to the macroeconomy are established. These approaches are still being used by many institutions, especially in emerging market economies, as they are tractable and easily understood by policy makers compared to some of the more data intensive and 
complex frameworks. In the latter frameworks, the mechanics underlying the model are hidden away and the intuition about the links to and influences from the macroeconomy is non-transparent or unavailable. Currently, there exists a substantial interest in connecting the macroeconomy to the financial sector more formally. This has led practitioners to use regression techniques to more explicitly link non-performing loans, loan loss provisions or probabilities of defaults to macroeconomic fundamentals (Sorge, 2004; Foglia, 2009).

The effect of macroeconomic variables on bank losses has also been analysed by means of loss distribution simulations, where the joint loss distribution of banks is constructed with Copulas (see Basurto and Goodhart, 2009; OeNB, 2010, among others). Others, such as De Nicolo and Lucchetta (2010) estimate factor models to study the systemic effects of financial stresses. The estimated models are subsequently used for forecasting purposes and to provide early warning signs of possible future financial crises.

Another stream of policy research has focused on accounting for feedback effects from the financial sector to the real economy. This is implemented by designing structural macroeconomic models (and more recently Dynamic Stochastic General Equilibrium models) where a financial sector is explicitly incorporated into the model to capture the systemic effects that the financial sector has on the real economy. The implementation of these models, nonetheless, comes at the cost of having a higher level of aggregation so that the risk profiles of individual banks and their heterogeneous behaviour is not studied (Kumhof, Muir, Mursula and Laxton, 2010; Christiano, Motto and Rostagno, 2010).

While retaining tractability, our methodology attempts to improve on existing approaches in the literature by linking the financial sector explicitly to the macroeconomy and accounting for both systemic risk factors due to changing macroeconomic conditions 
as well as for idiosyncratic risk factors due to the diverse lending practices and risk profiles of individual banks. It should be emphasised that each component of the proposed stress testing framework presently constitutes a separate research agenda in the literature. The objective of the proposed methodology is thus not to improve on current frontier models of the individual components, but rather to provide policy makers and practitioners with an integrated, flexible and policy relevant tool that can be readily implemented. We illustrate the usefulness of the proposed methodology for policy decision making with an empirical application to a set of Eastern European banks and an ensuing discussion of the results in regards to their potential implications for supervisors.

The remainder of the paper is structured as follows. Section 2 gives a conceptual outline of the proposed stress testing methodology. Section 3 discusses the generation of the macroeconomic scenarios. Section 4 shows how that the systemic and idiosyncratic risk factors are constructed. Section 5 describes the computation of credit risk exposures and exposures at default. Section 6 discusses the main stress test outcome indicators. Section 7 contains an empirical application of the proposed methodology using data of Eastern European banks. We also conduct a brief sensitivity analysis and discuss how to implement the proposed methodology under limited data availability. Section 8 concludes the study.

\section{Conceptual Outline of Proposed Stress Testing Approach}

We begin by providing a conceptual overview of the main segments of the proposed macroprudential stress testing methodology, which we summarise visually in a flow diagram depicted in Figure 1. The first segment of the stress testing methodology consists of the construction of three macroeconomic scenarios. These are as follows: 

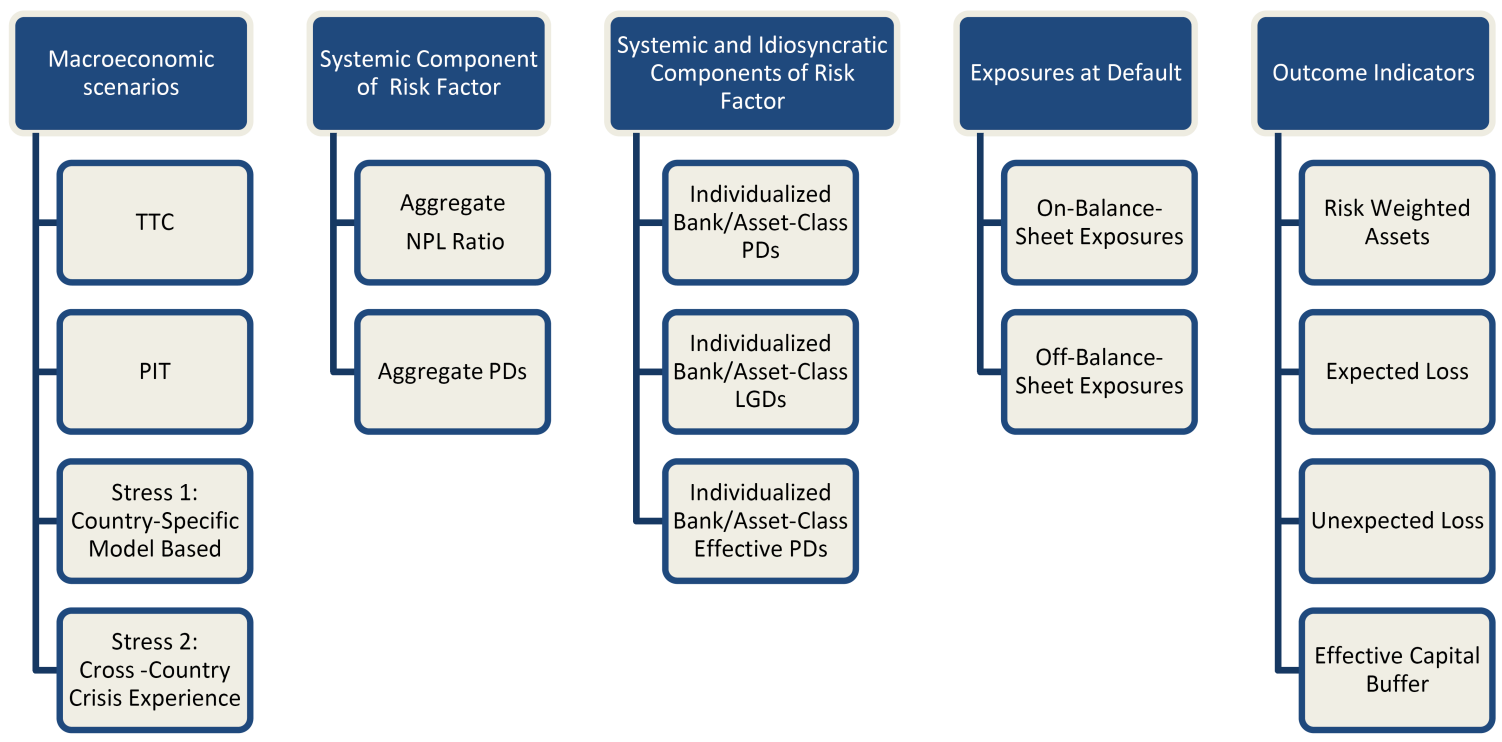

Figure 1: Conceptual overview of the main segments of the macroprudential stress testing methodology.

(i) Through-The Cycle (TTC) scenario,

(ii) Baseline Point-in-Time (PIT) scenario, and

(iii) Stress scenario.

The purpose of the TTC scenario is to quantify the equilibrium or the steady state of the economy. The baseline PIT scenario captures the predicted macroeconomic developments under normal economic conditions covering the time interval of the stress testing period which is typically one year and corresponds in principle to mean or consensus point forecasts over that interval. The Stress scenario is constructed from two different approaches: the first one is a model based, country-specific Stress scenario, where we use time series data to estimate a Vector Autoregressive (VAR) model to construct one year ahead forecast densities. For a given macroeconomic variable of interest, we then use either the upper or the lower $1 \%$ tail value of the forecast densities, whichever corresponds to the adverse scenario, as a Stress scenario. The second, model-free approach uses a panel of cross-country data that includes historical periods of financial crises. This effectively 
approximates a "real world" Stress scenario that captures the actual crisis experience of a large number of countries world wide. ${ }^{2}$ In Section 3 we discuss the construction of all three scenarios in more detail.

The second segment contains a mapping from each macroeconomic scenario to nonperforming loans (NPLs) and then to probabilities of default (PDs). ${ }^{3}$ This mapping has two parts. The first part uses the elasticity estimates of NPLs to a set of macroeconomic variables of interest to compute a predicted change in NPLs. The second part uses the uncovered interest parity (UIP) condition and the existing proportion of foreign currency (FX) denominated loans to relate exchange rate movements to changes in NPLs stemming from unhedged FX exposures of borrowers. Any risks arising from such unhedged exposures to exchange rate movements are hereby captured as indirect credit risk. It is further assumed that implied changes in NPLs due to changing macroeconomic conditions move proportionally to changes in PDs under each of the three macroeconomic scenarios that we consider. Increases in PDs are taken to be proportionally distributed across the asset class specific PDs under each scenario. ${ }^{4}$

Evidence from the global financial crisis has shown that during periods of financial distress the sensitivity of credit risk to changing macroeconomic conditions increases substantially. This observation has been emphasised previously in the literature by, among others, Drehmann and Manning (2004), Virolainen (2004), Alves (2004), Pesaran, Schuermann, Treutler and Weiner (2006), Peura and Jokivuolle (2004), and Bangia, Diebold, Kro-

\footnotetext{
${ }^{2}$ Note that this approach partly addresses the proposal of Breuer et al. (2009) to "shock" banks from alternative "angles" since the sensitivity of the loss distribution of the banking system varies with different macroeconomic shocks. So here we effectively employ two different ways to shock the banking system. Čihák (2007) makes a similar argument for reverse-engineering a shock scenario back from a desired outcome for the system, such as undercapitalisation of a certain percentage of banks.

${ }^{3}$ Note here that NPLs are measured as ratios and are computed as the share of non-performing loans in total loans. Throughout the text we will simply refer to this ratio as NPLs.

${ }^{4}$ Details regarding which asset classes we consider are provided later on in Section 4.1.
} 
nimus, Schagen and Schuermann (2002). We address this effect practically by using shortterm multipliers from the estimated NPL regression to approximate the mapping to NPLs in the PIT scenario (i.e., during normal times) and long-term multipliers in the Stress scenarios. This effectively introduces a non-linearity into the response of NPLs to the macroeconomic variables.

The third segment constructs bank-specific PDs and LGDs for each asset class. This is done by taking the aggregate PDs and weighting them by a bank and asset-class specific penalty function that is designed to approximate the relative underwriting standards of banks. The penalty function compares each individual bank's credit growth to the average credit growth of the entire banking system at the peak of the most recent credit cycle or the latest positive credit growth. The idea here is to approximate the "bad vintage effect" that arises due to weaker underwriting standards during credit booms by the relative aggressiveness of a bank's lending in each asset class. ${ }^{5}$ The bank and asset class specific PDs are then linked to LGDs by means of a correlation parameter. We follow the approach outlined in Moody's (2010) to calibrate this correlation parameter to be larger during stress times than during normal times.

The fourth segment constructs the exposures at default (EADs) for each bank using the asset class categories of Basel II. In principle, the EAD is composed of two types of exposures: (i) an on-balance sheet and (ii) an off-balance sheet exposure. Off-balance sheet exposures include items such as pre-approved limits for credit cards, overdrafts and credit lines. In some countries, these exposures are published as part of the Pillar III regulatory information disclosure for each bank and asset class and could therefore be

\footnotetext{
${ }^{5}$ For instance, during the last credit boom, most Eastern European countries experienced their fastest credit growth in 2007. Therefore, we use the growth in annual credit from $2006-2007$ in each asset class to construct the bank specific penalty later on in the empirical application in Section 7.
} 
publicly available.

In the fifth segment, the capital charge equation of Basel II (2006) is used to compute bank and asset class specific risk weights which incorporate an adjustment term for maturity mismatches based on the average residual maturity of a bank's asset class. Additionally, we include a penalty function to individualise asset performance correlations for each bank and asset class, based on the relative concentration of a bank's lending within that asset class. For this, we use the share of the ten largest borrowers in the asset class or the Herfindahl-Hirschman $(\mathrm{HH})$ index as a measure of concentration. ${ }^{6}$ We further condition the maturity transformation adjustment term on the average maturity of a bank's liabilities.

In the fifth segment we also compute a number of outcome indicators of interest. These include the difference between Loan Loss Reserves (LLR) and Expected Losses (EL) as a share of regulatory capital, which is an indicator of the scale of potential underprovisioning, along with the number of underprovisioned banks in the banking system and the absolute amount of missing provisions in the system. Further, we construct the effective capital buffer as the ratio of the regulatory capital adjusted for the difference between profits, loan loss reserves and expected losses to the risk weighted assets that account for the aggregate macroeconomic and bank specific economic risks that we consider.

\section{Construction of Macroeconomic Scenarios}

When constructing a macroeconomic scenario, it is important that a point of reference is established that corresponds to the long-run equilibrium or steady-state of the economic

\footnotetext{
${ }^{6}$ One can also use the regional and/or sectoral concentration of bank lending in that asset class as an alternative measure.
} 
system of interest. In what follows, the through-the-cycle concept provides such a reference point, where the steady-state is represented by the average value of the macroeconomic variables over a typical business or credit cycle. ${ }^{7}$ This concept and its relationship to the Point-in-Time and Stress concepts is illustrated in Figure 2.

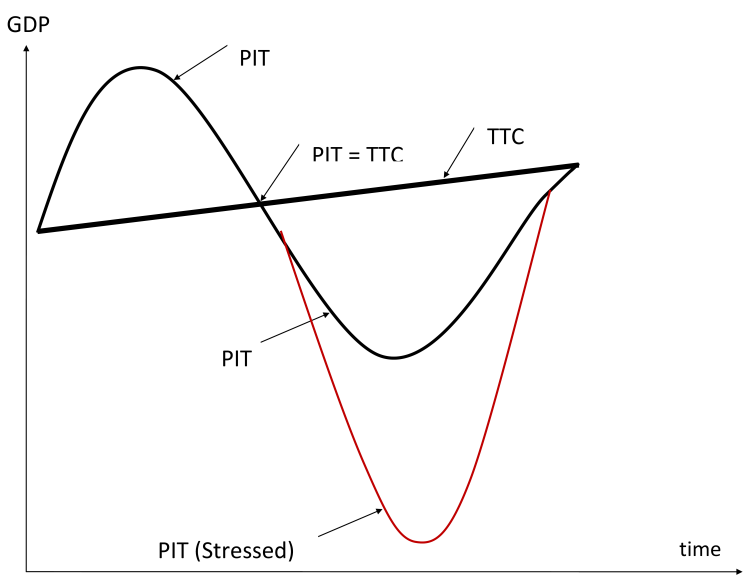

(a) Business Cycle

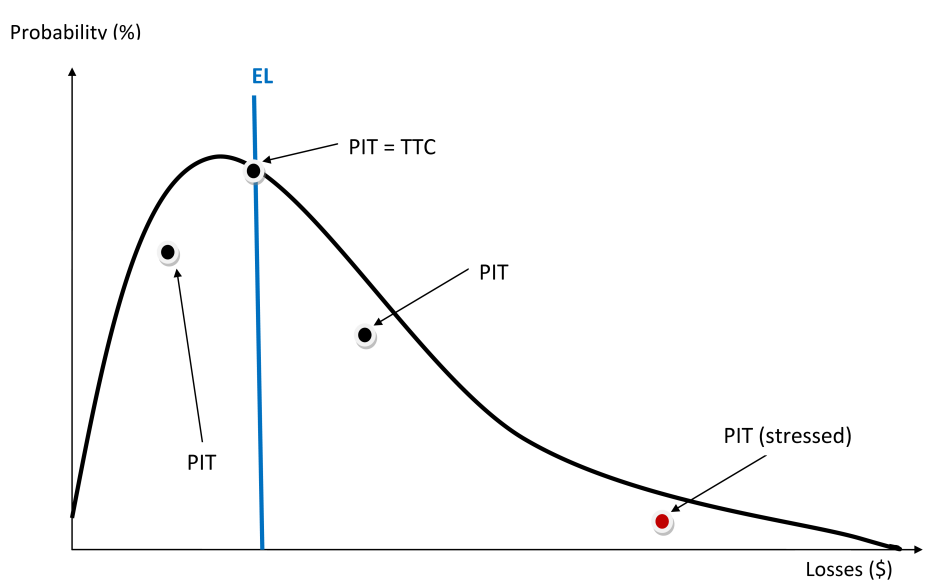

(b) Loss distribution

Figure 2: TTC, PIT and Stress Concepts in the context of a Business Cycle and the Value at Risk.

The left panel of Figure 2 shows the TTC, PIT and Stress scenarios in the context of a general business or credit cycle. Notice that the abnormal part of the business cycle (red line), which should be covered by capital buffers, causes the long right tail in the loss distribution that is shown in the right panel of Figure 2. Because of the skewness of the loss distribution, the expected loss (EL) over the business cycle is located to the right of the mode of the loss distribution. Expected losses thus correspond economically to the loan loss reserves which should be built up during the upside, and depleted during the downside of a regular business cycle. Loan loss reserves, nonetheless, are generally not intended to be used for hedging the unexpected losses (UL) in the downside of an

\footnotetext{
${ }^{7}$ We use the terms credit cycle and business cycle interchangeably in the description of the methodology, although they clearly do not need to be the same conceptually or empirically. Nonetheless, the terminology and the notion of a downturn (trough), an upturn (peak) and other related terms are also commonly used in the business cycle literature. For this reason we do not explicitly differentiate between the two.
} 
abnormally severe business cycle. For this purpose, capital buffers should be available and used.

We will first outline how the macroeconomic scenarios can be constructed before we describe how these macroeconomic scenarios are translated into the risk factors that are shown in the flow chart of Figure 1.

\subsection{TTC and PIT Scenarios}

Through-the-cycle (TTC) values of the macroeconomic variables of interest can be constructed in a number of different ways. The simplest way is to use the arithmetic mean computed from historical data. When this strategy is followed, care needs to be taken that the average is calculated over a sufficiently long horizon, covering preferably several business cycles, including normal as well as abnormal ones. It is particularly important to account for structural breaks and transitional convergence when these averages are computed for emerging market economies, as it is likely that steady-state values have changed over time. This can be achieved by employing statistical methods that are robust to structural changes and outliers. It may also be appropriate to consult expert judgment when dealing with substantial transitional or structural changes.

Another way to compute TTC values would be to use the unconditional means implied by a statistical model of the macroeconomy. The benefit of using this approach is the flexibility of being able to include structural shifts and dummy variables in the model if needed. Nonetheless, if the data span is too short, the cost of this approach is a decline in the precision of the estimated parameters needed to construct the unconditional means.

Point-in-time (PIT) values can also be obtained in a number of different ways. One possibility is to use consensus forecasts for the next four quarters from the relevant na- 
tional authorities such as the central bank and the national statistical agency or any other private or public agencies that compute such forecasts at the country level, including the Economic Intelligence Unit, the International Monetary Fund, the World Bank and other IFIs. If more than one such forecast is available and deemed relevant, one can simply compute the average over the different individual forecasts that are available. Alternatively, it is possible to get the PIT values from a model based forecast such as from a VAR model or any other structural model that is available for this purpose.

The Stress scenario can be seen as a special case of the PIT scenario and could thus be generated using projections from an estimated theoretical or statistical model while looking into the extremes of such projections. The extremes could be e.g. the $1 \%$ adverse percentile of the forecast distributions of the macroeconomic variables, in contrast with the mean or median forecast values used in the baseline PIT scenario. This ensures that empirical links (consistency) among the macroeconomic variables that form the Stress scenario is preserved. We propose such an approach in Section 3.2. ${ }^{8}$ However, there exists a criticism in the literature that mainstream macroeconomic models have rather too strong equilibrating properties that preclude one to adequately analyse large and sustained departures from the equilibrium (steady state), such as those characterising financial crises. For instance, Čihák and Schaeck (2010) argue for a non-parametric approach in calibrating relevant Stress scenarios. We propose a non-parametric approach in this spirit in Section 3.3 which is based on historical cross-country crises experience. Overall,

\footnotetext{
${ }^{8}$ Another, computationally more demanding way of constructing a model-based Stress scenario that we do not elaborate on in this study is the one proposed by Breuer et al. (2009). Breuer et al. (2009) suggest to specify a loss function that depends on macroeconomic variables of interest and then perform a "search" for the combination of adverse scenarios for the variables that produces the largest loss. In our setting the loss could be defined as the absolute financial loss for the entire banking system that is analysed. However one needs to put plausibility bounds on the macroeconomic variables before performing the search for the worst possible outcome based on the loss function. The resulting values of the macroeconomic variables that lead to the worst possible outcome are then considered as a Stress scenario.
} 
we acknowledge the benefits of using both parametric (model-based) and non-parametric (model-free) Stress scenarios and employ both in our proposed methodology.

\subsection{Country-Specific Stress Scenario}

A country-specific Stress scenario can in principle be generated from any statistical or macroeconomic model that is available for the economy of interest. The complexity of such a model could range from something simple such as a VAR model, to a structural econometric model or a fully fledged Dynamic Stochastic General Equilibrium (DSGE) model. ${ }^{9}$ The model that is used should be set up so that multiple step-ahead point and density forecasts can be readily computed. The lower (or upper) tail value of the forecast density can then be viewed as a model based adverse or Stress scenario. ${ }^{10}$

We propose to use a simple VAR model to construct the country-specific Stress scenario as a viable alternative to more complex structural models. The minimal VAR that is needed in the stress test should contain the four macroeconomic variables for which the NPL elasticities are estimated (see Section 4.2), as these represent the transmission channel from the economy to the banking system. The four required macroeconomic variables are the following:

(i) real GDP growth,

\footnotetext{
${ }^{9}$ As an example, a simple small scale New Keynesian model for an open economy is estimated in Buncic and Melecky (2008). The use of DSGE models in stress testing has been criticised after the global financial crisis due to their strong equilibrating properties which, as many argue, make them unsuitable for simulating the on-set and studying the adjustment process after a major stress to the economy. Nevertheless, there are arguments in favour of using some formal (structural) macroeconomic models to facilitate policy discussions between, for example, regulators and banks on the appropriate choice of magnitudes of the stresses to be applied and how these will most likely be transmitted through the financial system and the economy.

${ }^{10}$ Whether it is the upper or lower tail value depends on the macroeconomic variable for which the stress value is constructed. This will become clear later on. Also, if the forecasts of the model are based on simulation techniques so that draws from the forecast density are available, then one can simply look at the lower (or upper) percentile values as corresponding stress values.
} 
(ii) CPI inflation,

(iii) a lending rate and

(iv) the change in the nominal exchange rate.

Since many macroeconomic variables can be quite volatile in emerging economies, it is beneficial to use year-on-year changes when constructing the growth rates rather than annualised (multiplied by four) quarter-on-quarter changes. This is the approach that we follow later on in the empirical section of the paper.

To briefly illustrate the exact steps of how a VAR based Stress scenario can be constructed, consider for simplicity of exposition the following first order VAR model: ${ }^{11}$

$$
Y_{t}=C+A Y_{t-1}+U_{t}
$$

where $Y_{t}$ is a 4 by 1 vector containing the four macroeconomic variables listed above. The coefficient matrix $A$ captures the dynamics of the system and $U_{t}$ is a multivariate normal vector of disturbances with zero mean and variance-covariance matrix $\Sigma_{u}$.

One year ahead point forecasts are computed as the iterated (or dynamic) four period forecasts from the quarterly $Y_{t}$ series. That is, we use the forecast recursion

$$
\hat{Y}_{T+h \mid T}=\mu+A^{h}\left(Y_{T}-\mu\right)
$$

to construct the $h$ step ahead forecast, where $\mu$ is a 4 by 1 vector of the unconditional mean of $Y_{t}$ computed as $\mu=(I-A)^{-1} C$, with $I$ being a 4 by 1 identity matrix. Letting $\alpha$ denote

\footnotetext{
${ }^{11}$ In the empirical part of the paper we use standard statistical methods based on information criteria such as the Schwarz information criterion (SIC) and the Hanna-Quinn information criterion (HIC) to determine the optimal lag length in the VAR (see Ivanov and Kilian, 2005 for a review on lag selection in VARs).
} 
the statistical level of significance, given the multivariate normal assumption of $U_{t}$ in (1), we can construct $(1-\alpha) 100 \%$ forecast confidence intervals as

$$
\hat{Y}_{T+h \mid T, k} \pm z_{\alpha / 2} \sigma_{k}(h)
$$

where $\hat{Y}_{T+h \mid T, k}$ is the $h$ step ahead point forecast of the $k^{t h}$ variable in $Y_{t}, z_{\alpha / 2}$ is the upper $\alpha / 2$ percentage point of the standard normal distribution and $\sigma_{k}(h)$ is the square root of the $k^{\text {th }}$ diagonal entry of the $h$ step ahead forecast error variance-covariance matrix $\Sigma_{u}(h)$. The variance-covariance matrix $\Sigma_{u}(h)$ is computed from

$$
\Sigma_{u}(h)=\sum_{p=0}^{h-1} \Phi_{p} \Sigma_{u} \Phi_{p}^{\prime}
$$

where $\Phi_{p}$ is the $p^{\text {th }}$ term of the infinite Vector Moving Average (VMA) representation of the VAR in (1). Because the VAR model in (1) is of first order, we have that $\Phi_{p}=A^{p}$ for all $p=0,1,2, \ldots$ so that we can simply take powers of $p$ to get the $p^{\text {th }}$ term of the VMA (see Lütkepohl, 2005, pp. 22-24 and pp. 35-40).

Due to the multivariate normality of the $h$ step ahead density forecast, the model based Stress scenario is obtained simply as the adverse $(1-\alpha) 100 \%$ forecast confidence interval for the macroeconomic variables of interest. For the real GDP growth series, for example, it would correspond to the lower tail of the forecast confidence interval, while for the lending rate, it would be the upper tail value of the forecast confidence interval. The size of the $z_{\alpha / 2}$ term in the construction of the Stress scenario should be chosen in line with the risk preferences of the macroprudential supervisor. This value could be set to -2.3263 which would correspond to the lower $1 \%$ tail value under the standard normal density function, so that this adverse scenario would occur with $1 \%$ probability in a classical re- 
peated sampling context. ${ }^{12}$

As discussed, the model based Stress scenario, notwithstanding its benefits, is susceptible to the assumed parametric structure that is imposed on the data. We thus also propose an alternative non-parametric approach to construct the Stress scenario next.

\subsection{Stress Scenario Based on International Experience}

There can exist circumstances when it is not possible or acceptable to employ a model based Stress scenario, due either to the lack of available data to formulate a sufficiently adequate statistical model, or due to a less favourable view of statistical models inside the policy environment in general. With this in mind, we propose an alternative model-free approach, which we label "Stress International" (or Stress Int. for short). This approach looks at the actual historical evidence of countries that experienced a financial crisis in the past. Crisis periods are identified using the banking and currency crises dating database compiled by Laeven and Valencia (2008).

Given the crisis dates, we extract real GDP growth, CPI inflation, lending rates and changes in the exchange rate from the World Bank and the IMF's IFS databases for the countries (and years) that went through a financial crisis, and then look at the values of these macroeconomic variables during the crisis years. There are a total of 161 countries, covering crisis periods dating back as far as the early 1970s and including the most recent global financial crisis. We are interested in obtaining a representative scenario that captures the changes in the macroeconomic variables of interest for a typical crisis year based

\footnotetext{
${ }^{12}$ Note that the construction of the Stress scenario based on the adverse forecast confidence interval in (3) above relies on the assumption of $U_{t}$ being multivariate normal. This may or may not be appropriate. Should it not be appropriate, one can resort to re-sampling techniques such as bootstrapping to compute, say, 1000 bootstrapped forecast values, and then use the value corresponding to the $1^{\text {st }}$ percentile as a stress value for real GDP growth and the $99^{\text {th }}$ percentile for the lending rate.
} 
on the actual historical cross-country experience. ${ }^{13}$ Because of this, we do not take the minimum values nor the accumulated sums over a range of years surrounding the crisis as is done in Laeven and Valencia (2008), but rather use the single year values of the four macroeconomic variables of interest in the particular year that is identified as a crisis.

Note that two types of crises from Laeven and Valencia (2008) qualify as a financial crisis in the construction of our Stress scenario based on the cross-country experience. These are Systematic Banking Crises and Currency Crises, and the Stress scenario considers both. ${ }^{14}$ We compute the average response of the macroeconomic variables during the crisis years, where the average is taken over all the countries that experienced a financial crisis. However, since the database includes a large number of countries, there exist instances where some of the macroeconomic variables respond to the financial crisis in an economically counterintuitive manner, making it necessary to introduce some additional censoring rules to ensure that only economically meaningful responses are measured.

The following censoring rules were applied. Firstly, we arrange the data so that all crisis years are collected in a vector for each country that has gone through a financial crisis. We then look at the worst response in terms of GDP growth for each country by taking the minimum value over the different crises years. Ideally the minimum over the crises years should give us the worst case response for each country as actually experienced historically during a crisis period. Secondly, we take out countries for which the selected minimum values were positive, that is, when the change in GDP growth during the crisis years was greater than zero. This is necessary to avoid the inclusion of a coun-

\footnotetext{
${ }^{13}$ We do not use the crises summary statistics such as output loss and minimum real GDP growth that Laeven and Valencia (2008) calculate. The reason for this is that these statistics are computed over a time window of at least 3 years and up to 5 years around the crisis years. Laeven and Valencia (2008) thus effectively measure the overall cost of the crisis in terms of real GDP growth.

${ }^{14}$ Note that these two are often interconnected and referred to as twin crises (Kaminsky and Reinhart, 1999; Glick and Hutchison, 1999).
} 
try experience that contradicts the definition of a systemic financial crisis. ${ }^{15}$ Thirdly, we employ an outlier robust method to compute the average response of the countries that have experienced a financial crisis by computing trimmed means. The trimmed means are calculated in such a way that only the data points that fall within the $2.5^{\text {th }}$ and the $97.5^{\text {th }}$ percentile are included in the computation. This ensures that only the centre of the empirical data, where $95 \%$ of the probability mass lies, is included in the averaging. The influence of extreme values on the average response is thus effectively eliminated. The censoring rules applied to $\mathrm{CPI}$ inflation, the lending rate and changes in the exchange rate are analogous to the ones applied to real GDP growth.

One last requirement that is imposed is that for each country a full set of macroeconomic Stress scenarios needs to be present. That is, we require data for each of the four macroeconomic variables (real GDP growth, CPI inflation, the lending rate and the change in the exchange rate) to be available for the trimmed mean response to be computed. If, for instance, data on lending rates are not available for a particular country, while the remaining three macroeconomic variables are present, then this scenario, and potentially the country itself, is excluded from the calculation of the average crisis response. The resulting model free Stress scenario based on the historical cross-country crisis experience is reported under the Stress Int. heading in Table 3 in Section 7.

\footnotetext{
${ }^{15}$ To provide an example of such a scenario, consider Lebanon which is identified by the Laeven and Valencia (2008) database to have gone through a Systematic Banking and Currency Crisis in 1990. However, (annual) real GDP growth from 1989 to 1991 was $-42 \%, 26 \%$ and 38\%, respectively for these three years. So GDP growth was an astonishing 26\% and 38\% for the years from 1990 to 1991 (the year of the crisis and the following year) while GDP growth was negative before the financial crisis. This example of the actual historical experience of Lebanon is clearly an exception that does not follow the typical scenario of a deep downturn in economic activity during a financial crisis. Including such a country experience in the Stress scenario construction would thus not be very informative.
} 


\section{Linking Macroeconomic Scenarios to Credit Risk Factors}

We link the macroeconomic variables to the credit risk factors in two stages. In the first stage, the TTC macroeconomic scenario which corresponds to the steady-state reference point is linked to the reference TTC probabilities of default (PDs) and loss given default (LGDs). Then, the baseline PIT and Stress scenarios, which characterise the different levels of departure from the steady-state TTC scenario, are linked to NPLs and to PDs. We use short-term multipliers from a fitted dynamic NPL regression to approximate the mapping in normal times and use long-term multipliers in Stress scenarios. Empirical evidence suggests that credit risk factors are much more sensitive to changing macroeconomic conditions in crisis times than in normal times (Drehmann and Manning, 2004; Virolainen, 2004; Alves, 2004; Pesaran et al., 2006; Peura and Jokivuolle, 2004; Bangia et al., 2002). We further assume that the projected changes in NPLs under the PIT and Stress scenarios are proportional to the changes in PDs in the PIT and Stress scenarios, where the reference points are again the TTC PDs. This completes the mapping from the macroeconomic scenarios to the aggregate PDs, which represents the systemic component of credit risk.

In the second stage (see Section 4.6), we let the aggregate PDs be affected by idiosyncratic factors derived from the risk characteristics of each individual bank. We augment the aggregate PDs based on an assessment of each individual bank's risks. This is achieved by adding bank and asset class specific penalty functions that penalise banks which grew their credit portfolios at a faster rate than the "average" of the banking system.

Additionally, if data on foreign currency (FX) denominated lending at the bank level are available, we impose a penalty for above average FX lending at the individual bank as well as the asset class level. We assume that LGDs are correlated with PDs where the correlation is specified to be stronger in crisis times (Stress scenario) so that the effect of 
changing macroeconomic conditions is translated, through the PDs and LGDs correlation, from probabilities of default to losses given default (Altman, Resti and Sironi, 2002). We also consider the concentration of bank lending in each asset class as well as the average time-to-maturity in the individual asset classes in the computation of the effective PDs and therefore the effective capital buffer (see Section 6).

\subsection{TTC Macroeconomic Scenarios, PDs and LGDs}

The purpose behind using the TTC values of the macroeconomic variables and the TTC PDs and LGDs is to ensure that the cost of credit for banks in the steady-state of the macroeconomy is adequately accounted for. Most developing countries lack adequate data describing historical aggregate PDs and LGDs over a sufficiently long time period that includes a number of business/credit cycles. We thus suggest to use the TTC PDs and LGDs constructed by the Fifth Quantitative Impact Study (QIS5) of the Bank for International Settlements (BIS) (BIS, 2006). Table 1 below shows the magnitudes of the constructed PDs and LGDs for banks belonging to CEBS Group 1, CEBS Group 2 and non-G10 Group 2 countries. ${ }^{16}$

The reason why we show entries for CEBS and non-G10 Group 2 countries ${ }^{17}$ here is that the empirical application presented in Section 7 uses data for a group of Eastern European banks. Most of the banks in Eastern European countries are either national or regional banks, or subsidiaries of foreign banks, rather than international banks. Entries for G10 countries are also provided in the QIS5 study and can be retrieved as required.

\footnotetext{
${ }^{16}$ Banks that are classified as Group 2 banks are smaller relative to Group 1 banks and do not have any significant international activities. To be classified as a Group 1 bank, the following three criteria need to be satisfied: (i) the bank has a Tier 1 capital in excess of $€ 3$ billion, (ii) the bank is diversified and (iii) the bank is active internationally.

${ }^{17}$ This group includes the historical experience of developing countries such as Brazil, Chile, India, Indonesia, and Peru, and of some former transition economies of Central and Eastern Europe.
} 
Table 1: Selected Through-the-cycle Probabilities of Default (PDs) and Losses Given Default (LGDs).

\begin{tabular}{|c|c|c|c|c|c|c|}
\hline \multirow{2}{*}{ Asset Class } & \multicolumn{2}{|c|}{ CEBS-Group1 } & \multicolumn{2}{|c|}{ CEBS-Group2 } & \multicolumn{2}{|c|}{ non-G10-Group2 } \\
\hline & PDs & LGDs & PDs & LGDs & PDs & LGDs \\
\hline Corporates & 2.20 & 38.1 & 0.83 & 35.2 & 1.47 & na \\
\hline SMEs $^{(1)}$ & 3.26 & 38.8 & 3.66 & 31.7 & 4.31 & 49.6 \\
\hline Consumer Mortgage Loans & 1.52 & 21.4 & 1.39 & 21.4 & 17.72 & 40.4 \\
\hline Consumer Loans ${ }^{(2)}$ & 3.69 & 55.0 & 2.33 & 51.9 & 11.34 & 55.7 \\
\hline Other Consumer Loans & 4.33 & 47.9 & 2.32 & 42.2 & 6.22 & 45.1 \\
\hline Sovereigns ${ }^{(3)}$ & 0.13 & 27.7 & 0.04 & 38.2 & 0.24 & na \\
\hline $\operatorname{Banks}^{(4)}$ & 0.22 & 39.4 & 0.11 & 39.4 & 0.74 & na \\
\hline
\end{tabular}

Notes: ${ }^{(1)}$ Retail, ${ }^{(2)}$ QRE retail, ${ }^{(3)}$ loans to public institutions and state-owned enterprises, and ${ }^{(4)}$ loans to credit institutions. Data are taken from BIS (2006).

The main point of reference in our proposed stress testing approach is the steady-state of the macroeconomy which is associated with the equilibrium through-the-cycle PDs and LGDs. We then model departures from this steady-state under the PIT and Stress scenarios using a mapping that relates the changes in overall macroeconomic conditions to the changes in credit risk factors as captured by the PDs and LGDs. This is implemented by estimating the elasticities of NPLs with respect to the four main macroeconomic variables of interest. This systemic component of credit risk factors is discussed in the next section. The role of individual bank characteristics, i.e., the idiosyncratic component of risk factors, is described in Section 4.6.

\subsection{Estimating the NPL elasticities}

We obtain estimates of the elasticities of NPLs to the four macroeconomic variables of interest by means of a dynamic panel data regression, using a panel of 54 high and middle income countries and controlling for the degree of development, financial deepening, and dollarisation (euroisation). ${ }^{18}$ The sample consists of annual data over the period from

\footnotetext{
${ }^{18}$ The list of countries that was used in the computation can be obtained from the authors upon request.
} 
1994 to $2004 .{ }^{19}$ The parameters are estimated from the following model:

$$
\begin{aligned}
N P L_{t+1, n} & =c+\rho N P L_{t, n}+\beta_{1} \Delta y_{t+1, n}+\beta_{2} \pi_{t+1, n} \\
& +\beta_{3} r_{t+1, n}+\beta_{4} \Delta e_{t+1, n}+\beta_{5} Z_{t+1, n}+\varepsilon_{t+1, n} .
\end{aligned}
$$

The variable $N P L_{t+1, n}$ is measured as the ratio of non-performing loans to total loans. ${ }^{20}$ The variables $\Delta y_{t+1, n}, \pi_{t+1, n}, r_{t+1, n}$ and $\Delta e_{t+1, n}$ are real GDP growth, CPI inflation, the (ex post) real interest rate and the change in the nominal US dollar exchange rate for country $n$ at time period $t+1 . Z_{t+1, n}$ is a vector of variables, comprising the log of GDP per capita (constant 2000 US dollars), the credit to GDP ratio, and the share of FX loans in total loans, that control for the degree of development, financial deepening, and dollarisation (euroisation), respectively. The model is estimated on an unbalanced panel using the GMM estimator of Arellano and Bond (1991). The results are reported in Table 2. Since none of the control variables in the $Z_{t+1, n}$ vector are statistically significant in influencing the conditional mean of NPLs and the effect of the nominal exchange rate is also statistically negligible, we only report the regression estimates of the main macroeconomic variables of interest, which are also the variables that we work with empirically hereafter.

The insignificance of the exchange rate comes from the fact that in normal times a local currency depreciation has a positive income effect which increases the external compet-

\footnotetext{
${ }^{19}$ Estimating the NPL regression on a relatively short time sample covering a period during which a country could have gone through major structural changes in the financial sector could be problematic. Similarly, using country specific historical data especially for emerging countries, covers only a rather limited number of crises periods. For these reasons, we find the pooled regression approach preferable for the sake of robustness of the acquired estimates, as lower income countries develop and their own past experience may not be relevant in assessing the impact of possible future crises on their financial system and on the economy. Moreover, if more country specificity is desirable, the pooled regression estimates could be used as priors in a Bayesian estimation of the NPL regression, including also additional country specific variables, possibly also as latent variables (see, Brand, Buncic and Turunen, 2010, on how latent variables can be incorporated in a monetary polciy modeling environment)

${ }^{20}$ Note here again that we will simply refer to this variable as NPLs (non-performing loans) in the text.
} 
Table 2: NPL regression estimation results.

\begin{tabular}{|c|c|c|c|c|}
\hline Variable & Estimate & Std. Error & $p$-value & 95\% Confidence Interval \\
\hline NPL ratio $(t-1)$ & 0.670 & 0.138 & 0 & [ 0.398; \\
\hline GDP growth & -0.262 & 0.089 & 0.004 & {$[-0.438 ;-0.086]$} \\
\hline Inflation & 0.131 & 0.054 & 0.015 & [ 0.025 \\
\hline Real interest rate & 0.206 & 0.047 & 0 & 0.113 \\
\hline Constant & 0.086 & 0.102 & 0.402 & {$[-0.116 ; 0.288]$} \\
\hline Adj. R-squared & 0.69 & \multicolumn{3}{|c|}{$\mathcal{H}_{0}:$ No resid $\operatorname{AR}(1) z=-1.66 ;$ Prob $>z=0.0969$} \\
\hline $\mathrm{F}(4,246)$ & 45.86 & \multicolumn{3}{|c|}{$\mathcal{H}_{0}:$ No resid $\operatorname{AR}(2) z=-0.08 ;$ Prob $>z=0.9343$} \\
\hline Number of observations & 251 & \multicolumn{3}{|c|}{ Sargan test of over-identifying restrictions: } \\
\hline Number of countries & 54 & \multicolumn{3}{|c|}{ Chi2 $(16)=20.88 ;$ Prob $>$ Chi2 $(16)=0.1830$} \\
\hline
\end{tabular}

Notes: The estimates were computed with the Arellano and Bond (1991) estimator where a maximum instrument lag length of two was used.

itiveness, net exports, and thereby also the repayment capacity of borrowers in an open economy. During times of financial crisis, nonetheless, when the local currency is expected to depreciate substantially, the local currency value of FX denominated debt, as well as its servicing cost, can increase considerably. These increases thus lead to an impairment of the repayment capacity of the debt holder. So there are two effects of a local currency deprecation that work effectively in opposite directions: the first one is a positive income effect and the second is a negative balance sheet effect. The two opposing effects of a depreciation can result in the finding of a statistically insignificant effect of exchange rate changes on NPLs for economies with a significant proportion of unhedged foreign currency debt that have experienced periods of gradual as well as sharp depreciations of the domestic currency,

Since the NPL regression results in (5) are uninformative with respect to exchange rate changes, we ignore the positive income effect of a local currency depreciation and focus solely on approximating the balance sheet (or indirect credit risk) effect on unhedged FX 
borrowings. ${ }^{21}$ Indirect credit risk due to unhedged FX exposures played an important role in driving the overall credit risk during financial crisis periods, most recently in Eastern European countries. We use the assumption that a local currency depreciation has the same effect on NPLs as an increase in the lending rate. ${ }^{22}$ The sensitivity of NPLs to a local currency depreciation coming from the unhedged part of borrowers' FX exposures is then obtained as the product of the estimated elasticity on the lending rate and the share of FX lending. That is, the elasticity of NPLs to exchange rate changes in asset class $i$ of bank $j$ denoted by $\alpha_{i, j}^{F X}$, is computed as:

$$
\alpha_{i, j}^{F X}=\beta_{3} \times S F X_{i, j}
$$

where $S F X_{i, j}$ is the percentage share of foreign currency denominated lending in total lending in asset class $i$ of bank $j$ and $\beta_{3}$ is the coefficient on $r_{t+1, n}$ in (5). Notice here that we specify this elasticity at the asset class level of each bank, so it is implicitly assumed that such data are available. If this is not the case and only bank level, but no asset class specific data are available, then the $S F X_{i, j}$ term in (6) can simply be replaced by $S F X_{j}$ so that the resulting $\alpha_{j}^{F X}$ varies only across banks but remains fixed over the asset classes held by each bank. If bank level data are not available either, then $S F X_{i, j}$ could be set equal to the average share of FX lending in the banking system, resulting in every bank receiving the same sensitivity to indirect credit risk due to the local currency depreciation,

\footnotetext{
${ }^{21}$ We acknowledge that other estimation approaches could be employed to try to isolate and further emphasise the income and balance-sheet effects of a local currency depreciation on NPLs, such as, for example, including interactive crisis identification dummies, or interacting the exchange rate with the data on the portion of unhedged FX debt. However, we leave this investigation for future research.

${ }^{22}$ This relation can be derived from a standard UIP condition starting from its log-linear representation

$$
\Delta e_{t+1}=r_{t}-r_{t+1}^{*}+u_{t+1}
$$

where $u_{t+1}=e_{t+1}-E_{t}\left(e_{t+1}\right)$ is a zero mean forecasting error.
} 
i.e., one could set $\alpha^{F X}=\beta_{3} \times S F X$.

The summary of the estimation results reported in Table 2 shows that all the coefficient estimates have the expected sign and magnitude. Note again that these estimates are elasticities. This means that the coefficient on GDP growth measures the percentage change in NPLs to a $1 \%$ change in GDP growth. Thus, a coefficient value of -0.262 implies that a $1 \%$ drop in real output growth is expected to increase the proportion of non-performing loans in total loans by $0.262 \%$. Similarly, increases in lending rates and inflation are expected to lead to an increase in NPLs. The diagnostic tests that are reported in Table 2 indicate that the difference transformation used in the Arellano and Bond (1991) procedure appears to be appropriate as there is no indication of any statistically significant serial correlation in the residuals, with the residuals in general being reasonably well behaved for a sample of this size and the type of data that is used. Also, the over-identification test of Sargan (1958) for instrument exogeneity does not reject the null hypothesis of the instruments being exogenous.

It should be pointed out here that since NPLs are measured as a ratio, the dependent variable falls into the class of fractional response variables and is thus naturally bounded between 0 and $1(0 \%$ and 100\%). It would thus seem more appropriate to use an estimation approach that is explicitly designed for such variables, as, for example, the estimator proposed by Papke and Wooldridge (2008). Since the model is bounded between 0 and 1 , the issues that arise are similar to those encountered when using the linear probability model for a binary response variable. Nonetheless, it should be pointed out that nearly all data points cluster around the $3 \%$ to $40 \%$ interval. So this is reasonably far enough into the centre of the 0 and 1 interval. As the standard approach for fractional response variables is to use a Logit or Probit model, and as these models have a linear conditional 
mean at the centre of the $[0,1]$ interval, we found that there is little to be gained from using such an estimator. Additionally, the coefficients of a linear model are considerably easier to interpret for policymakers and can therefore be readily put into perspective in terms of their influence on NPLs.

\subsection{Macroeconomic Mapping in Normal versus Crisis Times}

It is evident from the relation in (5) that the mapping from the macroeconomic variables to NPLs is a linear one in the sense that we do not estimate a model that allows the parameters to take on different values, depending on whether we are in a crisis period or not. Nonetheless, the literature and evidence from the recent financial crisis suggest that credit risks become more responsive to worsening economic conditions during crisis times (Drehmann and Manning, 2004; Virolainen, 2004; Alves, 2004; Pesaran et al., 2006; Peura and Jokivuolle, 2004; Bangia et al., 2002).

Although it is possible to estimate a model that explicitly allows for a non-linear relationship between NPLs and the macroeconomic variables in crisis and normal times, we do not do so here and instead generate such a non-linearity artificially. ${ }^{23}$ This is achieved as follows. During normal times, the short-run elasticities $\beta_{k}, \forall k=1,2,3$ capture the mapping between NPLs and the macroeconomic variables. However in crisis times, when

\footnotetext{
${ }^{23}$ To estimate a genuine non-linear relationship one would require a suitable number of data points in the different crisis and non-crisis regimes. Also, it would be necessary to use a viable regime classifier if the crisis periods are to be determined exogenously. One could do this again by taking the crisis dating of Laeven and Valencia (2008). However, experimentation with a threshold type non-linear model where the identifiers were taken from Laeven and Valencia (2008) resulted in a number of unsatisfactory outcomes which lead us to discard these results. The issues that were faced were similar to the ones encountered in the construction of the Stress International scenario, i.e., there were instances when the response to a crisis in fact reduced the size of the coefficients on the macroeconomic variables, suggesting a reduced sensitivity of NPLs to worsening macroeconomic conditions. The difficulties are related to the relatively small sample of data that is available to carry out the estimation of the elasticities, the large variation of the data around the conditional means, and the low (annual) frequency of the available time series. See also Buncic (2011) on this issue in the context of non-linear exchange rate models.
} 
decision horizons are shorter due to panic effects, herd behaviour and increasing uncertainty about future developments, the economy as a whole and the repayment capacity of its agents in particular become more sensitive to changing macroeconomic conditions. We approximate this increased sensitivity simply by using the long-term multipliers pertaining to the estimated NPL regression, that is, by using $\lambda_{k}=\beta_{k} /(1-\rho), \forall k=1,2,3$ as the elasticity in crisis times, where $\rho$ is the coefficient on the one period lagged value of NPLs.

\subsection{Linking Macroeconomic Scenarios to Changes in NPLs}

The changes in NPLs in the future period due to changes in the macroeconomic variables under the different scenarios, are calculated as follows. Let future scenario $\mathbb{S}=$ $\{$ PIT, Stress $\}$, so that $\mathbb{S}$ corresponds to either the PIT or the Stress scenario. The change in NPLs under future scenario $\mathbb{S}$ denoted by $\triangle N P L_{t+1}^{\mathbb{S}}$ is then constructed by taking the difference between the future value of the macroeconomic variable of interest under scenario $\mathbb{S}$ and its TTC value, multiplied by the corresponding impact elasticity from the NPL regression in (5).

For example, suppose that we are interested in the PIT scenario so that $\mathbb{S}=$ PIT. If the TTC value of GDP growth is 3.20\% (0.032) and the future PIT value is $0.5 \%$ or 0.005 in time period $t+1$, then the change in NPLs, is calculated by taking the difference $\left(\Delta y_{t+1}^{P I T}-\right.$ $\left.\Delta y^{T T C}\right)=(0.005-0.032)$ and multiplying this difference by the corresponding impact elasticity of GDP growth of -0.262 . This yields a change in NPLs under the PIT scenario of $-0.262 \times(0.005-0.032)=0.007074$ or around $0.71 \%$. The entries corresponding to interest rate and inflation related changes are computed analogously. Notice that we do note write a time subscript on the TTC GDP growth term as this is a long-run equilibrium 
value and should not vary over time.

It should be emphasised here that the impact of changes in GDP growth, inflation and the interest rate on NPLs is symmetric by construction. In contrast to that, we specify the indirect credit risk effect of the exchange rate on NPLs, and thus on the bank credit portfolio, to be asymmetric. That is, if the local currency depreciates relative to the US dollar (or the euro), then there will be an increase in NPLs due to this depreciation. However, if there is an appreciation, this impact is restricted to be zero. We therefore do not allow for a positive balance-sheet effect on NPLs caused by the local currency appreciation. The indirect FX effect on NPLs is thus computed as

$$
\text { Indirect } \mathrm{FX}= \begin{cases}\left(\Delta e_{t+1}^{\mathbb{S}}-\Delta e^{T T C}\right) \times \alpha_{i, j}^{F X} & \text { if } \Delta e_{t+1}^{\mathbb{S}}<\Delta e^{T T C} \text { (depreciation) } \\ 0 & \text { if } \Delta e_{t+1}^{\mathbb{S}} \geq \Delta e^{T T C} \text { (appreciation) }\end{cases}
$$

where $\Delta e_{t+1}^{\mathbb{S}}$ is the change in the exchange rate in future time period $t+1$ under scenario $\mathbb{S}, \Delta e^{T T C}$ is the corresponding through the cycle equilibrium value of $\Delta e_{t}$ and $\alpha_{i, j}^{F X}$ is the impact elasticity computed in (6).

\subsection{Accounting for Macroeconomic Risks in Aggregate PDs: the Systemic Component of Credit Risk}

Given the changes in NPLs in scenario $\mathbb{S}$ computed in Section 4.4, and the benchmark TTC PDs and LGDs taken from the QIS5 study and reported in Table 1, we can construct the probability of default for asset class $i$ under scenario $\mathbb{S}$ as the sum of the TTC PDs for that asset class and an additional factor that is scaled by the influence of the macroeconomic variables in the considered scenario. To illustrate this computation, let $\triangle N P L_{t+1}^{\mathbb{S}}$ 
denote the change of NPLs in the future period under macroeconomic scenario $\mathbb{S}$, where $\mathbb{S}=\{P I T$, Stress $\}$ as before. Also, define the TTC PD for asset class $i$ as $P D_{i}^{T T C}$. The probability of default in macroeconomic scenario $\mathbb{S}$ for asset class $i$ (denoted by $P D_{i}^{\mathbb{S}}$ ) is then computed as

$$
P D_{i}^{\mathbb{S}}=\varphi \times \underbrace{\Delta N P L_{t+1}^{\mathbb{S}} \times \frac{\overbrace{P D_{i}^{T T C}}^{\text {weight }}}{\overline{P D^{T T C}}}}_{\text {macroeconomy }}+\underbrace{P D_{i}^{T T C}}_{\text {asset class }}
$$

where $\overline{P D}^{T T C}=\sum_{i=1}^{7} P D_{i}^{T T C} / 7$.

The $\triangle N P L_{t+1}^{\mathbb{S}}$ term captures changes in the aggregate NPLs of the banking sector due to changing macroeconomic conditions under the PIT and Stress scenarios. The $\varphi$ parameter expresses the degree of proportionality between the changes in NPLs and PDs. In empirical applications, one can consider values in the $0.6-1.0$ range depending on the definition and reporting standards for NPLs. For instance, if the NPLs are defined as 60-day overdue loans, one could consider a $\varphi$ parameter that is closer to 0.6. If NPLs are defined as category D and E classified loans, a value of $\varphi$ closer to 1 could be used.

The role of the term $P D_{i}^{T T C} / \overline{P D}^{T T C}$ in (8) is to weight the influence from the macroeconomic variables on the PDs by the relative size of the asset's probability of default. This weighting scheme therefore ensures that an asset class that is, in relative terms, more likely to default than another class when no macroeconomic shocks are considered is also more likely to default when macroeconomic shocks are accounted for. For instance, if an asset class is two times more likely to default than the average of the considered asset classes in the TTC scenario, it is also two times more likely to default than the average of the considered asset classes in a Stress scenario. Hence, the proportionality across the $P D_{i}^{T T C}$ values before and after macroeconomic shocks is preserved. The last term in (8) adds the 
TTC PDs specific to each asset class to the effect coming from the macroeconomy.

\subsection{Incorporating Bank Specific Characteristics: the Idiosyncratic Component of Credit}

\section{Risk}

We use data on credit (EAD) growth for each bank and each asset class before the peak of the last credit cycle, or the most recent positive credit growth if the cycle is in an upturn, to get a measure of the relative aggressiveness of bank lending. The intention here is to approximate the quality of the underwriting standards of the individual banks in each asset class relative to the average of the banking system. This is under the assumption that relatively more aggressive lending is associated with laxer underwriting standards.

To describe the construction of bank specific PDs, let $P D_{i, j}^{\mathbb{S}}$ denote the PD for bank $j$ holding asset class $i$ under scenario $\mathbb{S}$, where $\mathbb{S}$ is now re-defined as $\mathbb{S}=\{$ TTC, PIT, Stress $\}$ and thus includes the TTC scenario as well. Also, let $C G_{i, j}$ be annual credit growth in percentages before the cycle's peak, or the latest positive credit growth, for bank $j$ in asset class $i .{ }^{24} P D_{i, j}^{\mathbb{S}}$ is then computed as

$$
P D_{i, j}^{\mathbb{S}}=\underbrace{P D_{i}^{\mathbb{S}}}_{\text {aggregate }}+ \begin{cases}\kappa \times \overbrace{\frac{\left(C G_{i, j}-\text { median }\left(C G_{i}\right)\right.}{\left(\max \left(C G_{i}\right)-\text { median }\left(C G_{i}\right)\right.}}^{\text {individual bank level effect }} & \text { if } C G_{i, j}>\operatorname{median}\left(C G_{i}\right) \\ 0 & \text { otherwise }\end{cases}
$$

where $P D_{i}^{\mathbb{S}}$ is the aggregate PD for asset class $i$ under scenario $\mathbb{S}$ and the terms $\max \left(C G_{i}\right)$ and median $\left(C G_{i}\right)$ are the maximum and median values of credit growth in asset class $i$,

\footnotetext{
${ }^{24}$ When credit growth is just turning positive out of a downturn and the economy enters the recovery phase of a credit cycle, care needs to be taken when considering the latest figures as it may be still more appropriate to use the peak growth rates of the last credit cycle. Once the economy is considered to be above potential growth, i.e., in the boom phase of a credit cycle, the latest available credit growth figures should be considered.
} 
where these are taken over all banks in the financial system.

The $\kappa$ parameter in (9) is a scaling parameter that controls the penalty increase in PDs of banks that pursued a more aggressive credit growth than the average bank, where this average is again measured by the median value. Note that the $\kappa$ parameter also controls the proportion between the systemic and idiosyncratic credit risk components in $P D_{i, j}^{\mathbb{S}}$. This means that when $\kappa$ increases more than the increase in $P D_{i}^{\mathbb{S}}$, the extend to which the idiosyncratic component influences the $P D_{i, j}^{\mathbb{S}}$ relative to the systemic component increases as well. In general, we fix the $\kappa$ parameter to be in the $5 \%-10 \%$ range for the TTC and PIT scenarios and in the $10 \%-20 \%$ range for the Stress scenarios. Note here, that this calibration ensures that the systemic component dominates in Stress scenarios when $P D_{i}^{\mathbb{S}}$ increases more than $\kappa$. Notice again the asymmetry in how the bank specific PDs in (9) are constructed. If credit growth in asset class $i$ of bank $j$ is less than the average credit growth, then the probability of default in asset class $i$ of bank $j$ is equal to the aggregate $\mathrm{PD}$, that is, $P D_{i, j}^{\mathbb{S}}=P D_{i}^{\mathbb{S}} \cdot{ }^{25}$ If, however, credit growth for bank $j$ is greater than the average credit growth, then the probability of default under scenario $\mathbb{S}$ is scaled up by an amount that depends upon how much larger credit growth was for this bank in a given asset class, relative to the median credit growth in the entire system.

Due to the restriction of a zero weight when $C G_{i, j}<\operatorname{median}\left(C G_{i}\right)$, the scaling term $\left[C G_{i, j}-\operatorname{median}\left(C G_{i}\right)\right] /\left[\max \left(C G_{i}\right)-\operatorname{median}\left(C G_{i}\right]\right.$ is bounded between 0 and 1 . This implies that the maximum amount by which the PD for bank $j$ in asset class $i$ can increase over the aggregate TTC PD due to the penalty is given by the size of the scaling parameter $\kappa$. The effective bounds on $P D_{i, j}^{\mathbb{S}}$ are thus given by $\left[P D_{i}^{\mathbb{S}}, P D_{i}^{\mathbb{S}}+\kappa\right]$. Should it be the case that no annual credit growth data at the individual bank level are available, then the $\kappa$

\footnotetext{
${ }^{25} P D_{i}^{\mathrm{S}}$ is equal to the values obtained in (8), for the TTC, PIT and Stress scenarios.
} 
parameter can be set to 0 . The consequence of this is that each $P D_{i, j}^{\mathbb{S}}$ then collapses to $P D_{i}^{\mathbb{S}}$. This effectively results in each bank having the same PD for asset class $i$. Finally, notice that the scaling of the PDs is linear. Therefore, a bank that experienced credit growth in a particular asset class at twice the rate of another bank in that asset class will have a twice as large penalty increase in the probability of default compared to the other bank.

LGDs for the individual banks and asset classes under the different scenarios are constructed as follows. Let $L G D_{i, j}^{\mathbb{S}}$ be the Loss Given Default for bank $j$ in asset class $i$ under scenario $\mathbb{S}$. $L G D_{i, j}^{\mathbb{S}}$ is then computed as

$$
L G D_{i, j}^{\mathbb{S}}=\underbrace{L G D_{i}^{T T C}\left(\frac{P D_{i, j}^{\mathbb{S}}}{P D_{i}^{\mathbb{S}}}-1\right) \times \rho_{L G D, P D}}_{\text {individual bank level effect }}+\underbrace{L G D_{i}^{T T C}}_{\text {aggregate }}
$$

where $L G D_{i}^{T T C}$ is the through-the-cycle value of LGDs taken from the QIS5 study, $P D_{i, j}^{\mathbb{S}}$ are the values computed in (9), and the parameter $\rho_{L G D, P D}$ controls the extent of the correlation between LGDs and PDs. Note that there exists considerable evidence in the literature to suggest that $\rho_{L G D, P D}$ increases during crisis times, that is, under the Stress scenario (see, for instance, Altman et al., 2002). We therefore suggest to calibrate the $\rho_{L G D, P D}$ parameter in the $10 \%-20 \%$ range for the non-crisis TTC and PIT scenarios, and increase the $\rho_{L G D, P D}$ parameter to the $30 \%-50 \%$ range during crisis times (under the Stress scenario). The latter range corresponds to the preliminary results found in the study by Moody's (2010) for the global financial crisis period.

Notice from (10) above, that because the $P D_{i, j}^{\mathbb{S}}$ are bounded by $\left[P D_{i}^{\mathbb{S}}, P D_{i}^{\mathbb{S}}+\kappa\right]$, where $\kappa$ will be greater than 0 , the term $\left(P D_{i, j}^{\mathbb{S}} / P D_{i}^{\mathbb{S}}-1\right)$ will be 0 if $P D_{i, j}^{\mathbb{S}}=P D_{i}^{\mathbb{S}}$ and it will be equal to $\kappa / P D_{i}^{\mathbb{S}}$ if $P D_{i, j}^{\mathbb{S}}=P D_{i}^{\mathbb{S}}+\kappa$. This means that the relation in (10) gives bounds on the effective $L G D_{i, j}^{\mathbb{S}}$ of $\left[L G D_{i}^{\mathbb{S}}, L G D_{i}^{\mathbb{S}} \times \rho_{L G D, P D} \times \kappa / P D_{i}^{\mathbb{S}}\right]$. Since $\kappa$ enters the upper bound 
as a product term, it is again the case that if $\kappa=0$, the LGDs for each bank will be set to the aggregate $L G D^{\mathbb{S}}$ for that asset class.

\section{Exposures at Default}

We follow the general approach in the literature (see, for example, Bluhm, Overbeck and Wagner, 2003) and calculate the exposures at default (EADs) for the purpose of credit risk modelling as a weighted sum of on-balance sheet and off-balance sheet credit risk exposures. Off-balance sheet exposures include future drawdowns such as loan commitments, preapproved credit card exposures and revolving credits. We use the classification scheme of Basel II and split the credit portfolio into seven asset classes including:

(i) Corporates

(ii) SMEs (retail)

(iii) Consumer Mortgage Loans

(iv) Consumer Loans (QRE retail)

(v) Other Consumer Loans

(vi) Sovereigns (loans to public institutions and state-owned enterprises)

(vii) Banks (loans to credit institutions).

For the sake of simplicity and tractability, we abstract from all other types of credit risk exposures. ${ }^{26}$

\footnotetext{
${ }^{26} \mathrm{~A}$ detailed overview of other types of credit risk exposures can be found in BIS (2010).
} 
The exposures at default for bank $j$ in asset class $i\left(E A D_{i, j}\right)$ are constructed as the following weighted sum:

$$
E A D_{i, j}=E A D_{i, j}^{O N}+\delta_{i, j} \times E A D_{i, j}^{O F F}
$$

where $E A D_{i, j}^{O N}$ and $E A D_{i, j}^{O F F}$ are, respectively, the on-balance sheet and off-balance sheet EADs for bank $j$ and asset class $i$. Notice that the on-balance sheet EADs receive a weight of unity in the sum in (11), while the weight on the off-balance sheet EADs is determined by the $\delta_{i, j}$ parameter. ${ }^{27}$ For example, for loan commitments, $\delta_{i, j} \times E A D_{i, j}^{O F F}$ estimates the amount that bank borrowers will draw on in the case of a default. If off-balance sheet data are not available $E A D_{i, j}^{O F F}$ can be set to zero and the stress test can be conducted with only on-balance sheet data. The $\delta_{i, j}$ parameter corresponds to the credit conversion factor of Basel II, which could range from $10 \%$ for unconditionally cancellable commitments to $100 \%$ for committed credit lines. However, the calibration of $\delta_{i, j}$ is an empirical matter and depends on the circumstances of the specific economy and the banking system that is analysed, because there can be differences in how off-balance sheet credit exposures of, for instance, consumers and enterprises behave in default situations. Further, if banks operate based on business models that target different income segments of the population, it is useful to allow for bank and asset class specific differences in $\delta_{i, j}$.

The EAD is an estimate of a bank's potential exposure to a counterparty in the event and at the time of the counterparty's default, taking into account the period of one year or the time-to-maturity of the exposure, whichever is shorter. In this regard, it is common to assume a full or partial rollover of the exposures with a time-to-maturity of less than

\footnotetext{
${ }^{27}$ Off-balance sheet exposures include commitments (including liquidity facilities), unconditionally cancellable commitments, direct credit substitutes, acceptances, standby letters of credit, trade letters of credit, failed transactions and unsettled securities (Basel II, 2006).
} 
one year. Overall, we consider gross nominal amounts of the EADs and do not take into account credit risk mitigation measures such as guarantees, collateral or securities and on-balance sheet netting, as these are accounted for in the calibration of the LGDs.

\section{Construction of Outcome Indicators}

The summary outcome indicator that we focus on is the effective capital buffer (the economic risk weighted capital adequacy ratio; see equation (21) for the definition) that incorporates economic risks under the three different scenarios that we consider. In contrast to some other stress testing approaches (e.g., Schmieder, Puhr and Hasan, 2011), we do not focus on the conditional loss distribution at the different stages of a credit cycle when computing the effective capital buffer. We see the use of conditional loss distributions as an undesirable feature of an outcome indicator as these can introduce pro-cyclicality into the capital requirements of a bank, which should be avoided.

To illustrate the latter point, consider the four stylised loss distributions depicted in Figure 3. The green, orange and red distributions are conditional loss distributions that correspond to three different stages of a credit cycle. For simplicity, we can think of the green distribution corresponding to losses during an economic upturn, the red one during a downturn and the orange one to losses when the economy is thought to be close to its steady-state (equilibrium) level. The black distribution is the unconditional (or envelope) loss distribution that captures losses over an entire business cycle which contains upturns, downturns, as well as normal and crisis periods.

When a conditional loss distribution is utilised to conduct a stress test, one can start from any one of the three possible conditional distributions that are shown in Figure 3. 


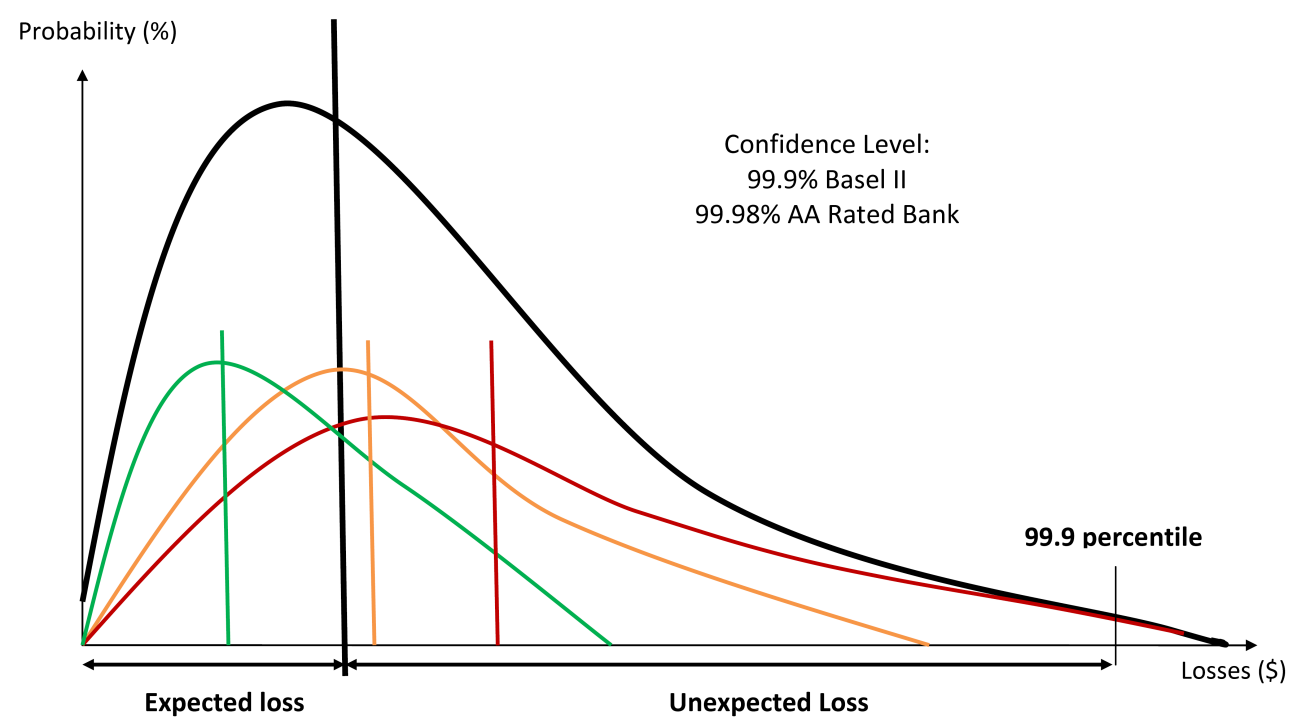

Figure 3: Unconditional and Conditional Loss Distributions.

Which one is used will evidently depend on the current state of the credit cycle of the economy. Suppose that the economy is thought to be close to its equilibrium, which would correspond to the orange loss distribution shown in Figure 3. When the supervisor conducts a stress test, a Stress scenario is applied from this "starting" point, resulting in the orange conditional loss distribution shifting to the position of the red loss distribution. Given the increased level of both expected and unexpected losses under the red distribution, the supervisor asks for additional capital in the magnitude that would cover the losses under the red distribution.

If, however, the current state of the economy is in an upside of a credit cycle, the same stress testing approach based on conditional loss distributions would start off from a distribution that corresponds to the upside of the credit cycle, that is, from the green loss distribution in Figure 3. After a similar level of stress is applied by the supervisor that caused the shift from the orange to the red distribution in the previous example, the green loss distribution would shift analogously to the position of the orange distribution. The latter is, however, not a loss distribution that would correspond to losses during periods 
of stress, as it is located around the steady-state of the credit cycle and the macroeconomy. Any increases in the capital requirements that the supervisor may ask for to cover the unexpected losses under this Stress scenario will be substantially lower, purely due to the fact that the conditioning loss distribution that one started from was the loss distribution corresponding to the upside of a credit cycle. Using conditional loss distributions thus introduces pro-cyclicality into the stress testing framework which should be minimised or, if possible, avoided altogether. ${ }^{28}$

The framework that we propose focuses on the use of an unconditional loss distribution, that is, a loss distribution that does not condition on the state of the credit cycle in the calculation of expected and unexpected losses, economic risk-based loan loss reserves and risk-weighted assets (RWA). Such an unconditional loss distribution is depicted in Figure 3 by the black distribution. Notice from Figure 3 that the unconditional distribution has several important properties. Firstly, its central tendency is calculated based on the TTC PDs and LGDs. Secondly, its tail is long and fat enough to cover the tail of the conditional distribution corresponding to the "over-the-cycle" Stress scenario. Thirdly, the unconditional loss distribution integrates the conditional distributions by taking their interdependence into account.

We thus emphasise that macroprudential stress tests should always start from an equilibrium or steady-state to ensure their consistent implementation over time. This is particulary important when the economy finds itself in an upturn, as starting from the "current" state of the economy (e.g. the upturn of the PIT scenario described in Figure 2) will often lead to the construction of benign and irrelevant stresses, and therefore also stress

\footnotetext{
${ }^{28}$ The positive association here is between the capital requirements and the location and dispersion of the conditional loss distribution, and not the capital requirements and the state of the economy that typically leads to the use of the term pro-cyclicality in the literature.
} 
test outcomes. The continuous reference of stress testers to an equilibrium value provides an anchoring point, so that macroprudential policy measures can be more consistently applied over time and over different stages of the business/credit cycle.

We find it also important to highlight that one should avoid the situation when, in an economic downturn, banks are asked by their supervisors to increase their capital levels, rather than having the necessary capital buffers built up before such a downturn occurs. Since unexpected losses and thus needed capital levels are assessed by means of stress tests, the procyclicality of current stress testing approaches should be minimised. This is not to suggest that banks were not be asked to increase their capital in an economic downturn in the past, however, it can prove very difficult for banks to raise new capital during times when funding in the economy is drying out and credit provision is being severely tightened. This is also likely to be counterproductive in facilitating a general economic recovery.

A challenge remains in practice to construct the unconditional loss distribution in such a way that it covers the tail of the unobserved conditional loss distribution in a Stress scenario. In this context, we find the guidelines in Basel II (2006) in terms of the suggested calibration of the correlations and maturity adjustments not very instructive, as the suggested calibration of the risk-parameters proved to severely underestimate those observed in reality during the global financial crisis. Rather than following this framework, we calibrate the asset performance correlations in the tail of the loss distribution based on the lending concentration of each individual bank in each asset class and the respective stress PDs. We also set the maturity adjustment penalty based on the actual average time to maturity for each asset class of the individual banks.

More specifically, we calculate Expected Losses $\left(E L_{i, j}^{\mathbb{S}}\right)$ for asset class $i$ and bank $j$ under 
scenario $\mathbb{S}=\{T T C, P I T$, Stress $\}$ as:

$$
E L_{i, j}^{\mathbb{S}}=P D_{i, j}^{\mathbb{S}} \times L G D_{i, j}^{\mathbb{S}}
$$

Expected losses for the TTC scenario thus correspond to the product of the individualised PDs and LGDs. Expected losses for the PIT and Stress scenario relate to the predicted losses conditional on the realisation of the considered macroeconomic scenario. Net losses $\left(\right.$ NetLoss $\left._{j}^{\mathbb{S}}\right)$ for each bank are computed as expected profits plus loan loss reserves less expected losses on the entire credit portfolio, that is:

$$
\operatorname{NetLoss}_{j}^{\mathbb{S}}=\text { Profit }_{j}^{\mathbb{S}}+\left(\text { Reserves }_{j}-\sum_{i=1}^{7} E L_{i, j}^{\mathbb{S}}\right) .
$$

TTC Profits can be computed as a long term averages based on, for example, historical Return on Assets (ROA) data. ${ }^{29}$ In order to compute PIT and Stress scenario Profits, a forecasting model is required, as forecasts need to be conditioned on the state of the economy. If no forecasting model is available, one can set the Profit term in (13) to zero for the PIT and Stress scenarios. ${ }^{30}$ This assumption is commonly adopted by stress testers and can be seen as a rather conservative estimate of profits.

We follow the guidelines in Basel II and compute Risk Weighted Assets (RWA) as:

$$
R W A_{i, j}=K_{i, j} \times 12.5 \times E A D_{i, j}
$$

where $K_{i, j}$ is the capital charge (or capital requirement) equation of Basel II (see page 64). ${ }^{31}$

\footnotetext{
${ }^{29}$ This calculation is thus the same as for the TTC macroeconomic scenarios in Section 3.1.

${ }^{30}$ We leave the estimation of a Profit regression using cross-country panel data for future research, and set the Profit term in the empirical application to zero for the PIT and Stress scenarios.

${ }^{31}$ These are the guidelines in the "Credit Risk - Internal Ratings Based Approach" section, with the rele-
} 
The capital charge is a function of each bank's PD, LGD, asset performance Correlation ${ }^{32}$ and maturity adjustment for the individual asset classes, conditional on the selected cutoff point of the loss distribution, ie., the risk preference parameter $\bar{c}$ in (16). It is computed as:

$$
K_{i, j}=\frac{\left[\left(L G D_{i, j}^{\text {Stress }} \times W_{i, j}\right)-\left(P D_{i, j}^{T T C} \times L G D_{i, j}^{T T C}\right)\right] \times\left[1+\left(M_{i, j}-2.5\right) \times b_{i, j}\right]}{\left(1-1.5 \times b_{i, j}\right)}
$$

where $b_{i, j}$ is the maturity adjustment term of Basel II, $M_{i, j}$ is the effective residual maturity of an asset class computed as the average of the residual maturity of loans within a given asset class weighted by the size of each loan. The term $W_{i, j}$ is computed as

$$
W_{i, j}=\Phi\left(\sqrt{\frac{1}{\left(1-R_{i, j}\right)}} \times \Phi^{-1}\left(P D_{i, j}^{T T C}\right)+\sqrt{\frac{R_{i, j}^{H}}{\left(1-R_{i, j}^{H}\right)}} \times \Phi^{-1}(\bar{c})\right) .
$$

The terms $\Phi$ and $\Phi^{-1}$ in (16) are the CDF and the inverse CDF of the standard normal density function, respectively. The risk preference parameter $\bar{c}$ is generally set in accordance with the risk preferences of the shareholders or the supervisor and defines the cut-off percentile value of the loss distribution, such as $99.9 \%$, up to which unexpected losses shall be hedged by capital. ${ }^{33}$

It is evident from (16) that, contrary to the Basel II formulas, we use two different types of asset performance correlations. The first one, denoted by $R_{i, j}$, is the standard one used in Basel II. The second one, which we denoted by $R_{i, j}^{H}$ in (16), is a function of the TTC PDs, vant formulas being on pages $63-64$ and $76-78$ for the different asset classes that are considered.

${ }^{32}$ In Basel II this is just referred to as Correlation (R).

$3399.9 \%$ is the value used in Basel II. 
the lending concentration (LendConc), and the Stress PDs, and is computed as:

$$
R_{i, j}^{H}=\xi_{i}+\theta_{i, j}+\zeta_{i, j}
$$

where the three components $\xi_{i}, \theta_{i, j}$, and $\zeta_{i, j}$ are, respectively, the floor of the asset performance correlation $\left(R_{i, j}^{H}\right)$ based on the relative TTC propensity to default for the considered asset class, an additive penalty based on bank and asset class specific lending concentration, and an additive penalty based on bank and asset class specific Stress PDs. The three components in (17) are calculated as:

$$
\begin{aligned}
& \xi_{i}=L B+\max \left\{0, U B^{\xi} \times \frac{\left[P D_{i}^{T T C}-\operatorname{median}\left(P D^{T T C}\right)\right]}{\left[\max \left(P D^{T T C}\right)-\operatorname{median}\left(P D^{T T C}\right)\right]}\right\} \\
& \theta_{i, j}=\max \left\{0, U B^{\theta} \times \frac{\left[\text { LendConc }_{i, j}-\operatorname{median}\left(\text { LendConc }_{i}\right)\right]}{\left[\max \left(\text { LendConc }_{i}\right)-\operatorname{median}\left(\text { LendConc }_{i}\right)\right]}\right\} \\
& \zeta_{i, j}=\max \left\{0, U B^{\zeta} \times \frac{\left[P D_{i, j}^{\text {Stress }}-\operatorname{median}\left(P D_{i}^{\text {Stress }}\right)\right]}{\left[\max \left(P D_{i}^{\text {Stress }}\right)-\text { median }\left(P D_{i}^{\text {Stress }}\right)\right]}\right\}
\end{aligned}
$$

where the max and median values in (18) are taken over the asset classes rather than over the banks, and $L B$ and $U B$ the lower and upper bounds of each component, respectively. ${ }^{34}$ We recommend to set $L B$ around 0.2. The three upper bounds $U B^{\zeta}, U B^{\theta}$ and $U B^{\zeta}$ need to be calibrated so that $R_{i, j}^{H}$ ranges between 0.3 and 0.5 . This recommended range is based on anecdotal evidence from interviews with bank credit risk officers on the impact of the global financial crisis.

The lending concentration term (LendConc) can be approximated as either the share of

\footnotetext{
${ }^{34}$ In (19) and (20), the max and median values are again taken over the banks as before.
} 
the ten largest exposures or as the Herfindahl-Hirschman $(\mathrm{HH})$ concentration index for each asset class and each bank. The $\xi_{i}$ component postulates that if a given asset class is relatively more prone to default in the TTC scenario compared to any other asset class, it will have a proportionately higher asset performance correlation during times of stress. For instance, we specify the Corporates asset class to have a floor correlation that is lower than Consumer Loans (QRE retail) in our empirical application. ${ }^{35}$

The $\theta_{i, j}$ component postulates that if an asset class of a given bank is more concentrated than the average bank in the system, where we again use the median value to measure this average, its asset performance correlation in the Stress scenarios will be proportionately higher. Similarly, the $\zeta_{i, j}$ component postulates that if a bank's Stress PDs in a given asset class are high compared to the average bank, the corresponding asset performance correlation will also be higher. Note that while $\xi_{i}$ takes into account only the relative propensity to default across the asset classes and not across the banks as the $P D_{i}^{T T C}$ term does not include the bank-specific component, the $\zeta_{i, j}$ component includes the variation in $P D_{i, j}^{\text {Stress }}$ across the banks as it includes the bank-specific component.

To summarise the above computations, we assume a lower asset performance correlation during normal times when the economy is closer to its steady-state value using the correlation measure $R_{i, j}$ of Basel II, and a higher correlation in the tail of the loss distribution when systemic risk factors are at their peak and all credit contracts are to some extent negatively affected during times of stress. This correlation is approximated by $R_{i, j}^{H}$ in (17). Note that, since a bank cannot influence any economic risk factors, only its risk exposures, it responds to materialising risks by adjusting its exposures (EADs). If the asset classes

\footnotetext{
${ }^{35}$ In principle, the floor per asset class can differ also across the banks based on their business models if relevant supervisory information is available - e.g. a bank, on average (through the cycle), being more regionally focused than other banks, or servicing a more vulnerable population or firms than other banks.
} 
have a long time to maturity (i.e. $M$ is large), it is much more difficult for the bank to adjust its exposures and, as specified in (15), it will have to bear greater losses when credit risks materialise.

The Economic Risk Weighted Capital Adequacy Ratio (ERW-CAR) under the three different scenarios is computed as:

$$
E R W-C A R_{j}^{\mathbb{S}}=\frac{\operatorname{RegCapital}_{j}-\mathrm{Net}_{\mathrm{Loss}}^{\mathbf{S}}}{\sum_{i=1}^{7} R W A_{i, j}}
$$

where $\mathrm{RegCapital}_{j}$ is the amount of eligible regulatory capital held by each bank (see also BIS, 2010), and $\mathbb{S}=\{$ TTC, PIT, Stress $\}$ as before. The through-the-cycle ERW-CAR corresponds to the situation when the macroeconomy is in its steady-state and banks are adequately provisioned so that dividends are paid out to shareholders based on bank profits and net losses are zero. Banks also have enough capital to meet the ERW-CAR based on the risk preferences of its shareholders or the macroprudential supervisor, whichever requirement is higher. In the PIT scenario, net losses are non-zero and the sum of the regulatory capital and net losses may or may not satisfy the supervisor's or shareholders' risk preferences. To appropriately test the capital adequacy conditional on the risk preferences of the shareholders or the supervisor, the Stress scenario and its impact on the ERW-CAR needs to be analysed.

Note that the three resulting ERW-CARs for each of the scenarios above have a different interpretation. For the TTC and PIT scenarios, which refer to a normal economic cycle, the computed ERW-CAR should be at or close to the regulatory requirement. In contrast to that, when the Stress scenario is evaluated, the implied ERW-CAR should stay above the insolvency limit of, for example, $2 \%$ or $0 \%$. Nonetheless, if the predicted net loss under 
the Stress scenario is positive or not significantly negative, care needs to be taken when analysing the stress test results, as a Stress scenario that does not lead to banks using their capital buffers should be regarded as irrelevant and not extreme enough. If this occurs when conducting the stress test, the supervisor should be alarmed because the stresses imposed on the banks may not be severe enough to be reliably used for macroprudential analysis. The design and the implementation of the stress test should be reconsidered.

To obtain a reliable overview of the financial system that is stress tested, we recommend that the ERW-CAR indicator be computed at different levels of aggregation, that is, at the individual bank level, the peer-group level and the system wide level. Further, we find it useful to examine not only the absolute level of the ERW-CAR relative to the existing regulatory requirements, such as the insolvency threshold or any other threshold that would trigger a prompt corrective action by the supervisor, but also the relative magnitudes across the individual banks. It should be clear from the outset of the stress test implementation that it is very difficult to design a stress test with an absolute focus in mind, in the sense that it will be very difficult to accurately quantify the outcome indicator of interest, such as the ERW-CAR, that will be attained by a particular bank (or the system) in absolute magnitudes. A stress test should rather be implemented and interpreted on a relative basis with the objective to identify problem banks relative to other banks in the system, and not to accurately quantify the absolute magnitude of an outcome indicator. This view is outlined and discussed in greater detail in Melecky and Podpiera (2010).

We also recommend that the distribution of the ERW-CAR of the entire system (or selected sub-system of banks) be examined before and after the application of the TTC, PIT and Stress scenarios. One should always monitor how the whole distribution, including its mean, median, dispersion and possibly skewness, changes for the peer-groups and for 
the entire system. The mean should be computed not only as a simple (equally weighted) average, but also as a weighted average, where the weights are determined by the size of the banks in the system, so that the influence of bigger banks is adequately captured by the summary statistics that are reported. The size of a bank can be approximated by its assets (or credits). We will refer to such a bank-size weighted average simply as "asset weighted mean" throughout the text. The aggregate summary statistics should provide useful indications of systemic risks within the system or across the peer-groups due to, e.g., common credit exposures, credit concentration and correlation of bank business models, system-wide weak loan origination and underwriting, and excessive, systemwide maturity transformations, regardless of whether or not such risks can be hedged away with derivatives.

\section{Empirical Application}

This section contains an empirical application of the proposed stress testing approach using data on a set of banks from an Eastern European country. We do not disclose the country or the names of the banks that are involved in the stress test as this is immaterial for the purpose of this study. The sole intention of the empirical application is to illustrate how the stress test can be implemented practically, what data inputs are needed, and how the results can be interpreted and used in a policy environment.

The banking system that is analysed consists of the ten largest banks in the country by asset size. Jointly they account for over $90 \%$ of the banking system as measured by 2010 assets. The banking system is fairly concentrated with the three largest banks accounting for around $2 / 3$ of the banking system. The remaining seven banks are approximately equally sized, accounting for less than $5 \%$ of the banking system each. In the results that 
we present here, we have sorted the banks according to size, so that the largest bank is Bank 1 and the smallest bank is Bank 10.

\subsection{Data Requirements and Calibration of Parameters}

\subsubsection{Macroeconomic Scenarios}

We initially construct the TTC, PIT and two Stress scenarios using the approaches described in Section 3. These scenarios are summarised in Table 3 below. We use quarterly data on GDP growth, CPI inflation, the lending rate, LCU/EUR exchange rate change, and non-performing loans as a proportion of total loans (NPLs). We work with fourth differences of the variables, i.e., four-quarter or year-on-year GDP growth, CPI inflation etc., measured in percentages.

Table 3: TTC, Baseline PIT and Stress Scenarios.

\begin{tabular}{lrrrrc}
\hline \multirow{2}{*}{ Macroeconomic Scenarios } & \multirow{2}{*}{ TTC } & \multicolumn{4}{c}{ Future $(t+1)$} \\
\cline { 3 - 6 } & & \multicolumn{1}{c}{ PIT } & Stress VAR & Stress Int. & Pr(Stress Int.) \\
\hline NPL ratio (\%) & $10.1 \%$ & $10.1 \%$ & $12.0 \%$ & $22.9 \%$ & $N A$ \\
GDP growth (\% change) & $3.2 \%$ & $0.5 \%$ & $-6.9 \%$ & $-6.3 \%$ & $86.7 \%$ \\
Inflation (\% change) & $2.8 \%$ & $2.4 \%$ & $11.7 \%$ & $26.5 \%$ & $99.8 \%$ \\
Real interest rate (\%) & $9.4 \%$ & $9.3 \%$ & $10.0 \%$ & $19.0 \%$ & $100.0 \%$ \\
Exchange rate (LCU/EUR) (\% change) & $0.0 \%$ & $0.0 \%$ & $0.0 \%$ & $-31.5 \%$ & $99.7 \%$ \\
\hline
\end{tabular}

Notes: A negative value $(-)$ in the (nominal) exchange rate denotes a depreciation of the Local currency unit $(\mathrm{LCU})$ relative to the EUR.

The TTC values are the long-run equilibrium values of the four macroeconomic variables of interest. We compute these equilibrium values as simple arithmetic averages using quarterly data over the period from 1996:Q1-2012:Q4. In addition, we use two yearahead consensus forecasts to increase the effective sample size when calculating these averages. Values used in the baseline PIT scenario are the market consensus forecasts. ${ }^{36}$ The

\footnotetext{
${ }^{36}$ One could also use the four step-ahead point forecasts from the VAR model.
} 
data for both the TTC and PIT scenarios were obtained from the Economic Intelligence Unit.

The country specific scenario labelled as "Stress VAR" in Table 3 is the four step-ahead dynamic forecast of the macroeconomic variables from a VAR(1) model. The stress values correspond to the adverse $1 \%$ tail values of the respective forecast distributions. The VAR(1) model was estimated on country specific data covering the period from 1996:Q12010:Q4, and standard lag length selection criteria were used to determine the appropriate lag order. The international Stress scenario based on the actual historical cross-country crisis experience is presented under the "Stress Int." heading. In addition, we compute the corresponding probabilities of the "Stress Int." values vis-a-vis the VAR(1) model forecast distributions, and report them in the last column of Table 3 under the $\operatorname{Pr}$ (Stress Int.) heading. ${ }^{37}$ The bank level balance sheet data are as of 2010:Q4.

Notice from Table 3 that under the TTC, PIT and Stress VAR scenarios the change in the nominal exchange rate is set to $0 \%$. This is due to the fact that the economy operates under a fixed exchange rate regime vis-a-vis the Euro, and we assume that the current conversion rate to the EUR is sustained under the TTC, PIT and country specific VAR Stress scenario. Nevertheless, since there exists ample historical evidence suggesting that exchange rate pegs break down or are abandoned by the authorities during severe financial crisis periods (Reinhart and Rogoff, 2004; Wälti, 2005) we also consider a 31.5\% depreciation of the local currency relative to the Euro under the "Stress Int." scenario. The magnitude of this depreciation was determined from historical cross-country data as

\footnotetext{
${ }^{37}$ These probabilities were constructed by taking the values under the "Stress Int." heading in Table 3 and plugging them into the four step-ahead multivariate normal forecast density of the VAR(1) model. The median probability is 99.7 percent so that the banks that need to preserve at least a BBB rating during times of a severe downturn should withstand this scenario without having their CAR fall under the insolvency threshold.
} 
described in Section 3.3.

\subsubsection{Bank Level Data}

The construction of the idiosyncratic (bank specific) risk component as described in Section 4 requires bank level data on credit growth at the peak of the last credit cycle or the most recent period of positive credit growth, and if available, data on the share of foreign currency denominated lending (SFX). Table 4 below shows summary statistics of annual credit growth in each asset class across the considered ten banks as of end-2007. The year 2007 marked the peak of the aggregate credit cycle for the subject economy, and between 2007-2010 annual credit growth was negative or around zero. Table 4 also shows summary statistics of the share of FX denominated lending in each asset class as of end-2010.

Table 4: Summary statistics of annual credit growth and the share of foreign exchange denominated lending for each asset class.

\begin{tabular}{|c|c|c|c|c|c|c|}
\hline \multirow{2}{*}{ Asset Class } & \multicolumn{3}{|c|}{ Annual Credit Growth in 2007} & \multicolumn{3}{|c|}{ Share of FX exposures in 2010} \\
\hline & Min & Median & Max & Min & Median & Max \\
\hline Corporates & $-2.5 \%$ & $40.6 \%$ & $66.5 \%$ & $30.4 \%$ & $69.8 \%$ & $90.9 \%$ \\
\hline SMEs $^{(1)}$ & $-42.9 \%$ & $9.2 \%$ & $146.1 \%$ & $7.1 \%$ & $45.3 \%$ & $82.0 \%$ \\
\hline Consumer Mortgage Loans & $-35.8 \%$ & $36.1 \%$ & $1185.7 \%$ & $7.1 \%$ & $45.3 \%$ & $82.0 \%$ \\
\hline Consumer Loans ${ }^{(2)}$ & $-97.5 \%$ & $17.9 \%$ & $345.0 \%$ & $7.1 \%$ & $45.3 \%$ & $82.0 \%$ \\
\hline Other Consumer Loans & $-85.1 \%$ & $90.1 \%$ & $1097.9 \%$ & $7.1 \%$ & $45.3 \%$ & $82.0 \%$ \\
\hline Sovereigns ${ }^{(3)}$ & $-92.8 \%$ & $0.0 \%$ & $73.6 \%$ & $0.0 \%$ & $66.5 \%$ & $100.0 \%$ \\
\hline $\operatorname{Banks}^{(4)}$ & $-100.0 \%$ & $0.0 \%$ & $300.0 \%$ & $7.2 \%$ & $49.2 \%$ & $100.0 \%$ \\
\hline
\end{tabular}

Notes: ${ }^{(1)}$ Retail, ${ }^{(2)}$ QRE retail, ${ }^{(3)}$ loans to public institutions and state-owned enterprises, and ${ }^{(4)}$ loans to credit institutions. Author's calculations.

It is evident from Table 4 that most of the credit growth at the peak of the last credit cycle occurred in the Other Consumer Loans asset class, which are typically secured loans such as car loans and loans for purchases of household appliances and electronics. Some banks also grew their mortgage portfolio fairly rapidly, starting from a relatively low basis. Most FX denominated lending was to Corporates, Sovereigns and Banks, but other 
asset classes also show a high exposure to FX denominated lending. Although we assume that Corporates are hedged against FX risk from 50\%, we are conservative with the treatment of individual retail borrowers such as SMEs and the three consumer loans asset classes, and assume that they are $100 \%$ unhedged against FX fluctuations. ${ }^{38}$

\subsubsection{Estimated Bank-Level PDs and LGDs}

Summary statistics of the estimated PDs and LGDs including the aggregate macroeconomic (systemic) and bank level (idiosyncratic) risk factors, as described in Section 4, are reported in the top and bottom panels of Table 5. Recall that the bank specific PDs and LGDs in (9) and (10) have an additive structure, where we add the individual bank specific terms to the aggregate asset class specific PDs and LGDs. Therefore, the respective aggregate PDs and LGDs for each asset class correspond to the values reported in the "min" column of each scenario in Table $5 .{ }^{39}$ In the construction of the LGDs we set the correlation between PDs and LGDs (as captured by the $\rho_{L G D, P D}$ parameter in (10)) to $20 \%$ in the TTC and PIT scenarios and to 50\% in the two Stress scenarios.

\subsubsection{Credit Risk Exposures, Loan Concentration and Residual Maturity}

The calculation of expected losses and capital charges for each bank in the system, outlined in Section 6, requires data on exposures at default, asset class concentration as well as the residual loan maturity for each asset class. Summary statistics for these quantities for the seven different asset classes across the individual banks as of end-2010 are shown in Table 6. The "AW" column under "Exposures at Default (EAD)" in Table 6 shows the

\footnotetext{
${ }^{38}$ Note that the ability of Corporates to generate foreign currency denominated revenue is given by the export share of their production. Although this share can hold even during crisis times as a percentage of income, the volume of these exports can rapidly decline when external demand cools down.

${ }^{39}$ Recall that the bank specific PD is equal to the aggregate PD for a particular asset class if credit growth for that bank was below the median value of the banking system, and the lending in FX was zero or the local currency depreciation did not occur.
} 


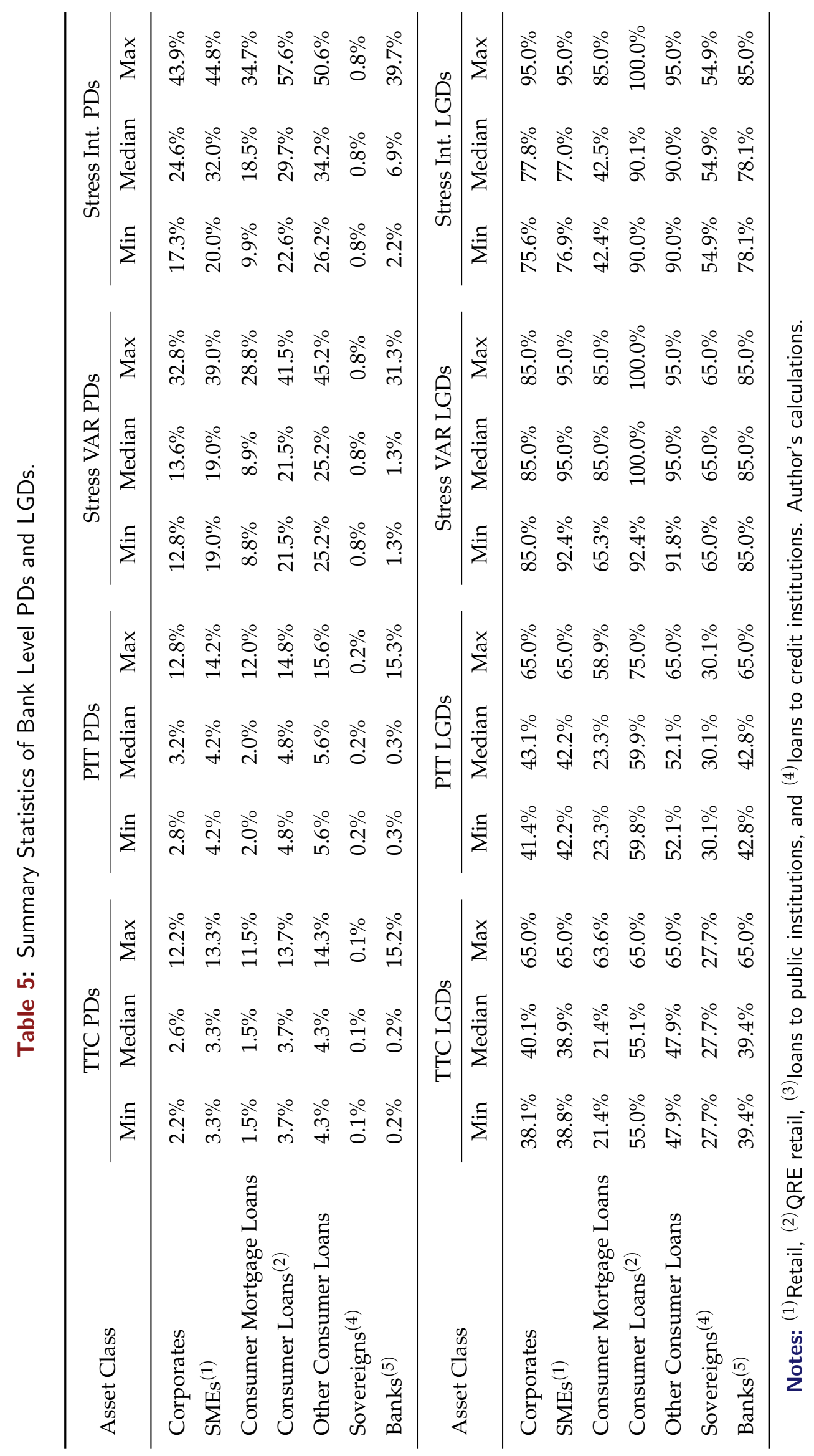


asset weighted mean for each asset class to account for the size of the bank in the computation of these averages. We measure asset class concentration as the share of the ten largest borrowers, and residual maturity is measured in years.

Table 6: Summary Statistics of Credit Exposures (EAD), Asset Class Concentration and Residual Maturity for 2010.

\begin{tabular}{|c|c|c|c|c|c|c|c|c|c|c|}
\hline \multirow{2}{*}{ Asset Class } & \multicolumn{4}{|c|}{ Exposures at Default (EAD) } & \multicolumn{3}{|c|}{ Asset Class Concentration } & \multicolumn{3}{|c|}{ Residual Maturity } \\
\hline & Min & Median & Max & $\mathrm{AW}$ & Min & Median & Max & Min & Median & Max \\
\hline Corporates & $32.5 \%$ & $59.7 \%$ & $88.3 \%$ & $60.5 \%$ & $11.8 \%$ & $28.5 \%$ & $55.9 \%$ & $1.5 \%$ & $2.8 \%$ & $5.7 \%$ \\
\hline $\operatorname{SMEs}^{(1)}$ & $0.0 \%$ & $0.2 \%$ & $28.3 \%$ & $1.8 \%$ & $11.8 \%$ & $28.5 \%$ & $55.9 \%$ & $0.0 \%$ & $2.8 \%$ & $4.1 \%$ \\
\hline Consumer Mortgage Loans & $0.1 \%$ & $7.7 \%$ & $18.6 \%$ & $7.5 \%$ & $4.3 \%$ & $37.8 \%$ & $100.0 \%$ & $4.2 \%$ & $14.9 \%$ & $17.6 \%$ \\
\hline Consumer Loans ${ }^{(2)}$ & $0.3 \%$ & $12.8 \%$ & $31.1 \%$ & $11.5 \%$ & $0.1 \%$ & $2.5 \%$ & $14.6 \%$ & $0.0 \%$ & $1.0 \%$ & $4.6 \%$ \\
\hline Other Consumer Loans & $4.5 \%$ & $10.8 \%$ & $37.5 \%$ & $17.9 \%$ & $4.9 \%$ & $44.3 \%$ & $95.5 \%$ & $3.3 \%$ & $5.4 \%$ & $11.7 \%$ \\
\hline Sovereigns $^{(3)}$ & $0.0 \%$ & $0.1 \%$ & $0.8 \%$ & $0.3 \%$ & $N A$ & $N A$ & $N A$ & $0.0 \%$ & $0.0 \%$ & $0.0 \%$ \\
\hline $\operatorname{Banks}^{(4)}$ & $0.0 \%$ & $0.1 \%$ & $2.6 \%$ & $0.6 \%$ & $N A$ & $N A$ & $N A$ & $0.0 \%$ & $0.1 \%$ & $2.3 \%$ \\
\hline
\end{tabular}

Notes: ${ }^{(1)}$ Retail, ${ }^{(2)}$ QRE retail, ${ }^{(3)}$ loans to public institutions and state-owned enterprises, and ${ }^{(4)}$ loans to credit institutions. Residual maturity is the average residual time to maturity measured in years. The "AW" column under the EAD heading measures the Exposures of the banking system computed as an asset weighted mean to account for the size (measured by assets) of the different banks in the construction of the aggregate average.

The summary statistics in Table 6 indicate that banks are most exposed to the Corporates asset class, which accounts on average for around $60 \%$ of their credit portfolio. This is true for both big and small banks as the median and the asset weighted mean for the system shown under the AW column are fairly similar. Some differences for Other Consumer and SMEs Loans are visible though. Namely, the asset weighted mean is somewhat larger than the median in these two cases, suggesting that bigger banks allocate relatively more credit exposure to these asset classes than small banks. The overall exposure to the Consumer group is the second biggest, with a median (asset weighted mean) value of over $31 \%(36 \%)$ for the three consumer loan segments in total. This is due to the rapid increase in consumer lending during the most recent credit boom.

On average, lending to Corporates and SMEs is considered to be highly concentrated with the average share of the ten largest borrowers being around 30\%. However, Other 
Consumer Loans and Consumer Mortgage Loans are the most concentrated asset classes. This could be due to these asset classes being small in absolute value and the youngest addition to the banking books of Eastern European banks. ${ }^{40}$

A longer average residual time-to-maturity in each asset class is a proxy for the time a bank would need to adjust its exposures to a given asset class in the case of a severe financial distress to contain mounting financial losses. Consumer Mortgage Loans have, on average, the longest residual maturity among the considered asset classes. Although the median value of 15 years is comparable to developed countries, the latter have significantly deeper mortgage loan markets and also very liquid secondary markets during normal economic conditions. Other Consumer Loans have an average time to maturity of over five years. Loans to Corporates and SMEs have average times to maturity of around three years, with a maximum of six and four years, respectively. Loans to Banks are the most liquid in terms of having the shortest average residual maturity, with only three banks having a loan residual maturity of more than one year.

\subsection{Results of the Stress Test}

\subsubsection{Aggregate Results for the Banking System}

The aggregate stress test results for the entire banking system are presented in Table 7 . The top part of Table 7 (under the Current Regulatory CAR heading) shows summary statistics for the current regulatory CARs held by the banks. The system wide averages are again measured by the median value and the asset weighted mean. The standard deviation captures the dispersion of the current regulatory CARs held by the banks. The minimum regulatory CAR is $8 \%$ for this banking system and the CAR insolvency threshold is $2 \%$.

\footnotetext{
${ }^{40}$ Many banks in Eastern European countries have expanded their Consumer Mortgage Loans and Other Consumer Loans portfolios fairly rapidly and aggressively over the last decade.
} 
The bottom part of Table 7 (under the Economic Risk Weighted Approach heading) shows the outcome indicators for the banking system based on economic risk considerations. The bottom part of Table 7 is split into an upper and lower part, where the upper part reports summary statistics for the ERW-CAR, and the lower part shows the intermediate calculation of Provisions minus Expected Losses in relation to expected losses and capital for the three different scenarios. ${ }^{41}$

Table 7: Summary of Aggregate Stress Test Results.

\begin{tabular}{|c|c|c|c|c|}
\hline \multicolumn{5}{|c|}{ Current Regulatory CAR (as of end-2010) } \\
\hline \multicolumn{5}{|l|}{ Regulatory CAR held at Banks (Banking System) } \\
\hline Capital Buffer (\%) - Asset weighted mean & & & & $13.8 \%$ \\
\hline Capital Buffer (\%) - Median & & & & $16.7 \%$ \\
\hline Capital Buffer (\%) - St.Dev. & & & & $4.9 \%$ \\
\hline Minimum Regulatory CAR & & & & $8 \%$ \\
\hline CAR Insolvency Threshold & & & & $2 \%$ \\
\hline \multicolumn{5}{|c|}{ Economic Risk Based Approach (as of end-2011) } \\
\hline Economic Risk Weighted CAR (Banking System) & TTC & PIT & Stress VAR & Stress Int \\
\hline Capital Buffer (\%) - Asset weighted mean & $10.3 \%$ & $10.0 \%$ & $4.3 \%$ & $0.4 \%$ \\
\hline Capital Buffer (\%) - Median & $10.8 \%$ & $10.6 \%$ & $4.2 \%$ & $0.4 \%$ \\
\hline Capital Buffer (\%) - St.Dev. & $3.1 \%$ & $3.1 \%$ & $3.5 \%$ & $4.7 \%$ \\
\hline Undercapitalization (\% of Profits) & $14.2 \%$ & $16.0 \%$ & $17.7 \%$ & $129.2 \%$ \\
\hline \# of Banks with Effective Capital Buffer $<8 \%$ & 2 & 2 & 9 & 9 \\
\hline \# of Banks with Effective Capital Buffer $<2 \%$ & 0 & 0 & 2 & 6 \\
\hline Provisions - Expected Losses (Banking System) & TTC & PIT & Stress VAR & Stress Int \\
\hline Number of under-provisioned banks & 1 & 1 & 9 & 10 \\
\hline$\%$ of Expected losses & $-34.0 \%$ & $-38.6 \%$ & $-48.4 \%$ & $-63.2 \%$ \\
\hline$\%$ of Capital (Tier $1+$ Tier 2) & $-10.9 \%$ & $-13.4 \%$ & $-51.0 \%$ & $-103.8 \%$ \\
\hline$\%$ of Capital (Tier 1) & $-16.4 \%$ & $-20.0 \%$ & $-66.3 \%$ & $-132.7 \%$ \\
\hline
\end{tabular}

Notes: Author's calculations. Note that TTC and PIT "Undercapitalization ( $\%$ of Profits)" is calculated to satisfy the $8 \%$ Regulatory CAR, whereas under Stress VAR and Stress Int. it is calculated not to be less than the Insolvency Threshold of $2 \%$.

The current regulatory CAR section of Table 7 suggests that the banking system is

\footnotetext{
${ }^{41}$ In the discussion that follows, we focus on the comparison between the Current Regulatory and the ERW-CAR indicators only and provide the results of the Provisions - Expected Losses calculation as background information without any further discussion.
} 
adequately capitalised based on existing regulation. Specifically, both the system-wide median and asset weighted mean indicate that banks, on average, hold capital well above the minimum regulatory requirement of $8 \%$. The regulatory CAR calculation is based on a modified Basel I approach. However, once economic risks are taken into account and the asset's risk weights are individualised by bank and by asset class according to our proposed methodology, there are some results that require the supervisor's attention. These results are shown in the bottom part of Table 7. Under the TTC scenario, when the economy and the credit cycle are assumed to be at the steady-state level, the median (asset weighted mean) ERW-CAR for the system stands at 10.3\% (10.8\%).

Further, given the regulatory requirement of keeping the CAR above $8 \%$, two banks fall short of meeting this requirement in the TTC scenario, once economic risks are accounted for. It is also interesting to note that the dispersion measured by the standard deviation of the ERW-CARs is noticeably smaller than the dispersion of the regulatory CARs. A possible interpretation of this finding is that banks optimise their capital allocation based on economic risks and once such economic risks are reflected in the asset's risk weights, banks appear more alike in terms of their capitalisation levels. This is in contrast to the regulatory CARs which do not reflect such economic risks. Notice from the PIT heading in the bottom part of Table 7, that the results for the Point-in-Time scenario are very similar to the TTC ones, so that the current macroeconomic conditions for the two coincide. ${ }^{42}$ It should be noted here that the TTC and PIT scenarios should be passed by all banks without any indication of a weakened financial condition. The Stress scenarios, nonetheless, are constructed to force the banks into using their capital buffers so that underprovisioning (fully used-up loan loss reserves) is envisaged, but banks should stay

\footnotetext{
${ }^{42}$ This can easily occur when PIT=TTC as shown in Figure 2 in Section 3.
} 
above the insolvency threshold of $2 \%$.

The results for the country-specific Stress scenario shown under the "Stress VAR" heading indicate that the median ERW-CAR for the whole system would decline to a value of $4.2 \%$ when economic risks are properly considered. More specifically, nine banks will have to draw on their capital buffers as their ERW-CARs drop below the $8 \%$ minimum capital adequacy requirement. Two banks would fall under the insolvency threshold of $2 \%$ and would be considered "failing" banks. All other banks are able to withstand the assumed country-specific Stress scenario. To recapitalise all banks in the system to the extent that a $2 \%$ ERW-CAR would be maintained in the Stress VAR scenario requires about $18 \%$ of the annual TTC profits generated by the entire banking system. This figure is arrived at by assuming a 3\% TTC Return on Assets (ROA) during normal economic conditions. This figure can also be calculated as a simple arithmetic average on historical ROA data. ${ }^{43}$ Profits for each bank are then calculated as ROA times Total Assets and are subsequently summed to provide a banking system wide measure of profits. We use TTC profits here as the base, because banks would normally use retained profits to gradually build up their capital buffers to the required level. ${ }^{44}$

The results of the Stress scenario based on the historical cross-country crisis experience under the "Stress Int." heading indicate that, on average, the capital buffers of the banking system would get reduced to $0.4 \%$, should this scenario occur. More specifically, nine banks would use their capital buffers, falling below the $8 \%$ minimum regulatory CAR level, and six banks would become insolvent with their ERW-CARs falling below $2 \%$.

\footnotetext{
${ }^{43}$ This corresponds to through the-cycle profits because the (unconditional) averages are computed over different stages of the business cycle and also preferably over a number of different business cycles.

${ }^{44}$ However, note that capital injections, coming either from existing or new shareholders, or from public resources (e.g. the government budget), could also be applied as a viable recapitalisation measure. These would be particularly relevant when the recapitalisation needs of the affected bank are so high and immediate that it could be considered a "failing" bank.
} 
Nevertheless, four banks would still have capital buffers strong enough to withstand such a severe credit risk shock. Recapitalising all banks so that they would withstand this Stress scenario, i.e., bringing their ERW-CARs above the $2 \%$ level, requires about $130 \%$ of the annual TTC profits generated by all banks.

The extent of the recapitalisation needs is substantial. However, given that we are working in the tail of the loss distribution, it becomes difficult to make precise statements about potential losses in absolute magnitudes. As discussed earlier, looking at the relative rather than absolute standing of banks during a Stress scenario could be a more informative way of identifying problem banks in the system. Individual bank results are thus discussed in the next section.

\subsubsection{Bank Level Results}

The bank level results for the ten banks in the system are summarised graphically in Figure 4 and Figure 5. The left panel of Figure 4 shows a comparison between the economic risk weighted CARs and the existing regulatory CARs held by each bank under the TTC scenario. The right panel of Figure 4 shows the corresponding recapitalisation needs in terms of bank profits to bring the ERW-CARs above the $8 \%$ threshold. Recall that the banks are sorted by asset size where the largest bank in the system is Bank 1 and the smallest bank is Bank 10.

The left panel in Figure 4 shows that for all banks the ERW-CARs are considerably smaller than the current regulatory CARs. The gap seems to be larger for smaller banks, which are more likely to hold more concentrated credit portfolios. ${ }^{45}$ Smaller banks also extend more foreign currency denominated lending to unhedged borrowers than bigger

\footnotetext{
${ }^{45}$ The portfolio concentration appears to be roughly two times bigger for banks with an above median asset size than for those with a below median asset size.
} 

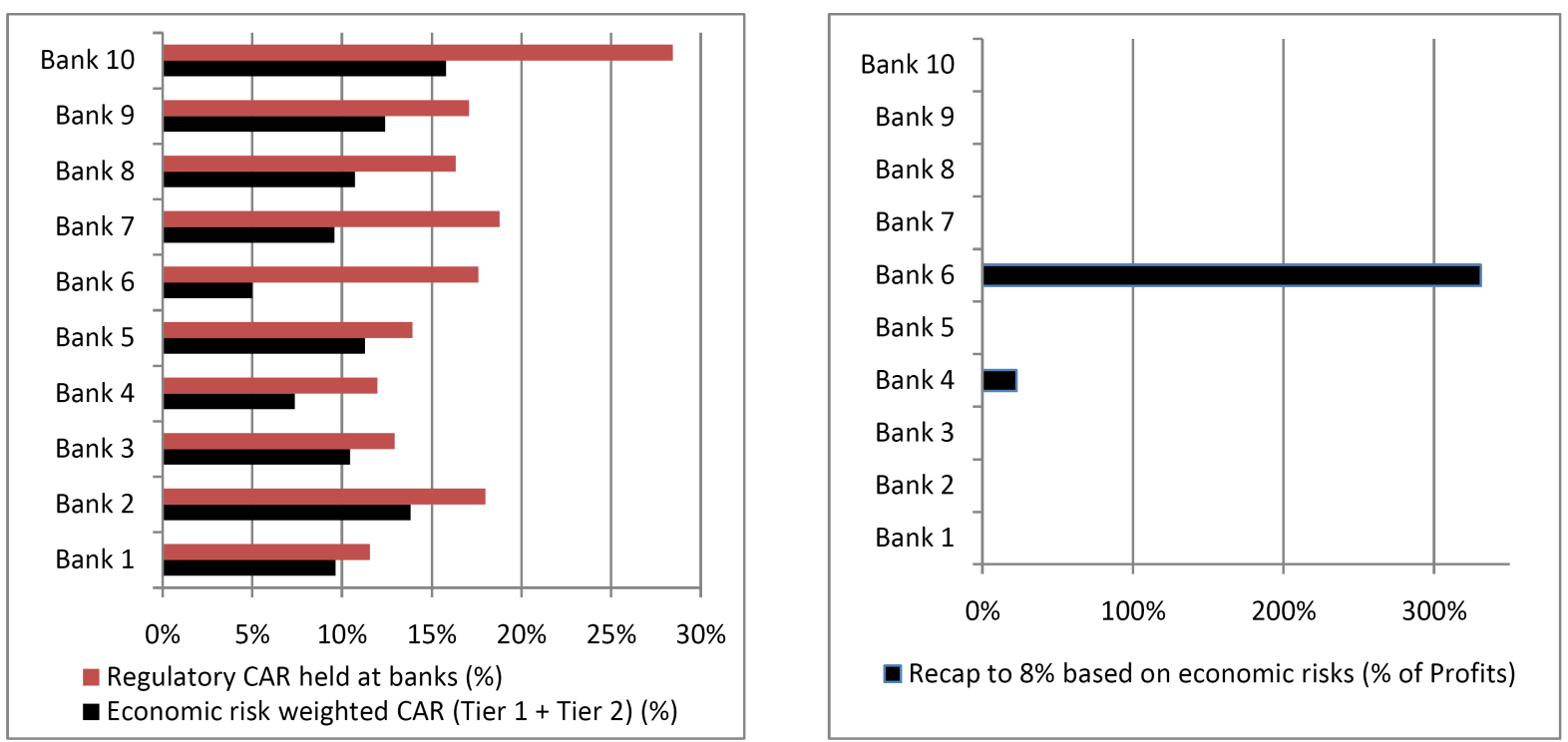

Figure 4: Economic Risk Weighted versus actual Regulatory CARs and Recapitalisation Needs by Bank for the TTC Scenario.

banks. The biggest difference between the regulatory CAR and the ERW-CAR is shown by Bank 6 and Bank 10. For these two banks, the current regulatory capital requirements could be significantly underestimating the capital needed to ensure adequate financial soundness and resilience.

The right panel of Figure 4 shows the recapitalisation needs to bring each bank above the $8 \%$ threshold based on the ERW-CAR. This recapitalisation requirement is again expressed in terms of the assumed annual TTC profits based on a 3\% ROA. Bank 6 and Bank 4 are the only two banks in our system that will need to inject additional capital to reach the $8 \%$ threshold based on the ERW-CAR. In terms of annual TTC profits, this quantity is around $25 \%$ for Bank 4 . For Bank 6, the extra capital requirements are substantially higher, exceeding $300 \%$ of annual profits. Given the results of the TTC scenario, Bank 6 could be considered a problem bank in the system and may require attention of the prudential supervisor.

Figure 5 summarises the bank level results for the two Stress scenarios. The left panel 
of Figure 5 shows the ERW-CARs under the Stress VAR and Stress Int. scenarios for each bank. The right panel of Figure 5 shows the capital requirements, as the percentage of annual TTC profits, that are needed to bring the ERW-CAR above the $2 \%$ insolvency threshold.

Figure 5 indicates that the most vulnerable banks are Bank 6 and Bank 4 which were identified earlier, as well as Bank 5 and Bank 7. The most resilient banks are the three smallest banks in the system (Bank 10, 9 and 8) and Bank 2. Assuming that the supervisor requires the banks to raise their ERW-CAR above the $2 \%$ insolvency threshold, Bank 6 and Bank 4 would need the largest amounts of capital to be injected relative to the remaining banks. Under the Stress Int. scenario, the magnitude of the additional capital required is around $600 \%$ of annual TTC profits for these two banks. Bank 5 and Bank 7 need approximately $350 \%$ and $250 \%$ of annual profits, respectively. Across the two different Stress scenarios that we consider, Bank 6 and Bank 4 are identified as the most vulnerable banks in the system.
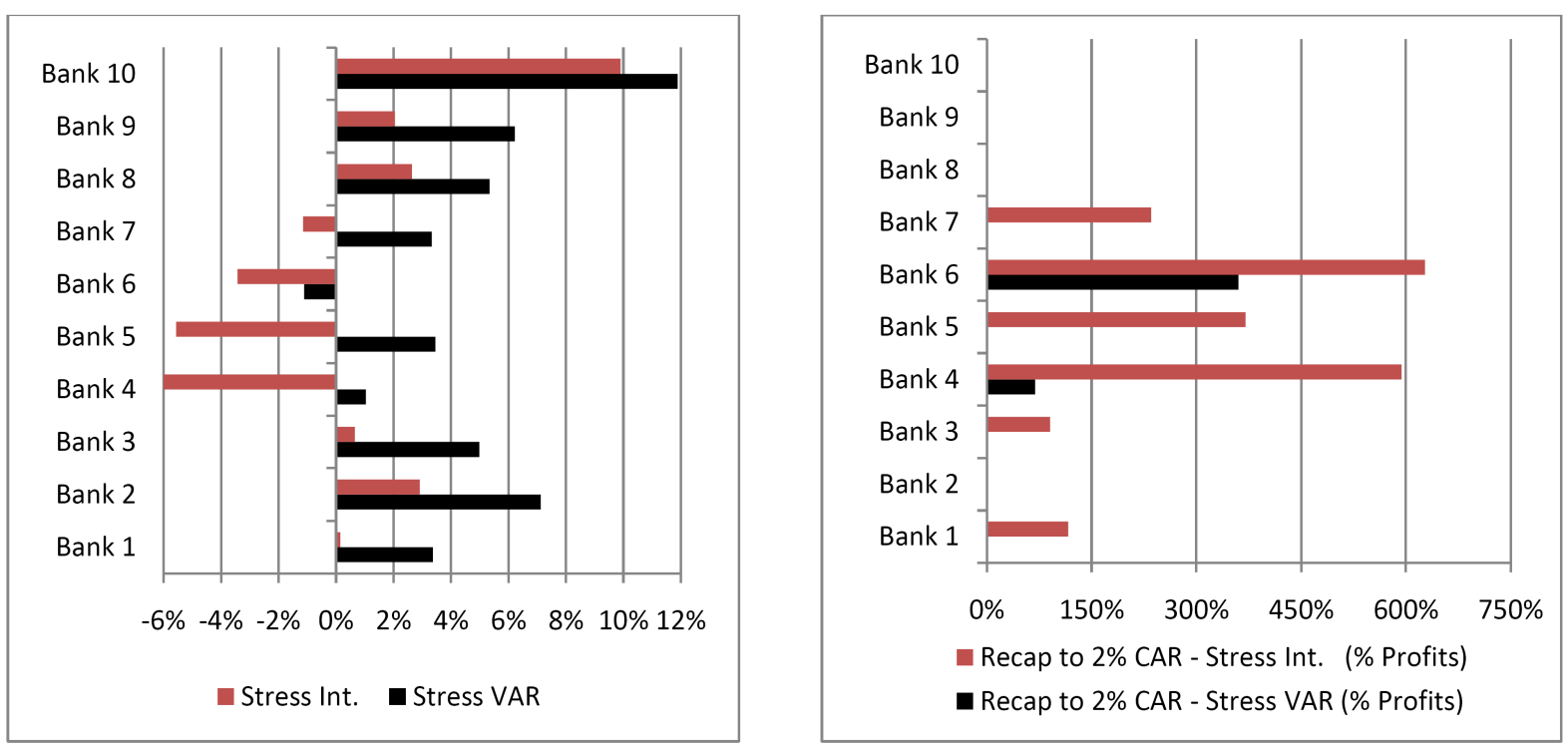

Figure 5: Economic Risk Weighted CARs and Recapitalisation Needs by Bank for the two Stress Scenarios. 
Overall, the presented empirical results point to the need to better align the capitalisation requirements with the individual risk profiles of the banks. The prudential supervisor can achieve this by adjusting asset risk weights across the board (or for selected asset classes), applying individual capital surcharges to the identified problem banks, or by developing individual adjustment programs for the most vulnerable banks in the system to reduce their key risk exposures under a suitable supervisory arrangement. The key risk factors that the supervisor could address are the maximum share of FX denominated lending, the lending concentration within the individual asset classes, the maximum maturity transformation that a bank can perform, and the overall concentration of a bank's lending across the asset classes.

\subsubsection{Sensitivity of Outcome Indicators to Changes in Calibrated Parameters}

As the suggested stress testing framework relies on a number of calibrated parameters, we find it informative here to provide a compact sensitivity analysis that shows how responsive the outcome indicators of interest are with respect to changes in some of our key calibrated parameters. The parameters that we look at are:

(a) the $\kappa$ parameter in (9) which controls the penalty increase in the bank specific PDs for banks that were more aggressive in their lending than the average bank in the system

(b) the asset performance correlation parameter $\rho_{L G P, P D}$ in (10)

(c) the risk preference parameter $\bar{c}$ in the capital charge equation in (16)

(d) and the assumption that a 50\% share of FX denominated exposures of Corporates is hedged by corresponding FX revenues. 
The alternative calibrations that we consider, as well as their impact on some of the outcome indicators that we focus on, are reported in Table 8 below. The sensitivity analysis points to a greater sensitivity of the "Stress Int." scenario results to the calibration of $\kappa$ than the TTC scenario results. This could be explained by the nature of the PD related penalty function in Basel II in the capital charge calculation which is exponential and flattens out at greater PD values. This functional form is motivated by an assumption that, in normal times, there exists a diversification effect at higher PDs that reduces asset performance correlation and thus capital requirements. However, this effect declines exponentially with increasing PD values (Basel II), such as those in our stress scenarios. On the other hand, the calibration of $\rho_{L G P, P D}$ has a greater influence under the TTC scenario, supposedly because there are greater relative differences in PDs (and therefore LGDs and expected losses) under this scenario, owing to the dominance of the idiosyncratic risk factor over the systemic one. By far the greatest influence that spans over both the TTC and Stress Int. scenarios comes from changes in the $\bar{c}$ parameter which cuts off the portion of unexpected losses that should be hedged by capital holdings - and thus expresses the risk aversion of the supervisor or shareholders. Changes in the degree to which Corporate FX exposures are hedged by Corporates' FX revenues have an impact only under the Stress Int. scenario when a local currency depreciation vis-a-vis the EUR is considered. This impact is significant and underscores the importance of analogous assumptions in stress tests applied to banking systems with a high share of FX lending.

\subsubsection{Application of the Approach when no Bank-by-Bank Supervisory Data are Available}

We will briefly discuss in this section how the proposed stress testing approach can be implemented when bank-level supervisory data are not available and the stress tester needs to rely on publicly available data sources. First, we assume that an accounting and 
Table 8: Impact of alternative parameter calibrations on stress test outcome indicators.

\begin{tabular}{|c|c|c|c|c|}
\hline \multirow{2}{*}{ Banking System/Sensitivity Parameter } & \multicolumn{2}{|c|}{ TTC } & \multicolumn{2}{|c|}{ Int. Stress } \\
\hline & kappa $=5 \%$ & kappa $=10 \%$ & kappa $=10 \%$ & kappa=20\% \\
\hline Effective Capital Buffer (\%) - Asset-Weighted Average & $10.9 \%$ & $10.3 \%$ & $0.7 \%$ & $0.4 \%$ \\
\hline Effective Capital Buffer (\%) - Median & $11.3 \%$ & $10.8 \%$ & $0.7 \%$ & $0.4 \%$ \\
\hline Effective Capital Buffer (\%) - St.Dev. & $2.7 \%$ & $3.1 \%$ & $4.4 \%$ & $4.7 \%$ \\
\hline Effective Undercapitalization (\% of Profits) & $4 \%$ & $14 \%$ & $105 \%$ & $129 \%$ \\
\hline \# of Banks with Effective Capital Buffer $<8 \%$ & 1 & 2 & 9 & 9 \\
\hline \multirow[t]{2}{*}{ \# of Banks with Effective Capital Buffer $<2 \%$} & 0 & 0 & 6 & 6 \\
\hline & rho(LGD, $P D)=10 \%$ & rho $(L G D, P D)=20 \%$ & rho(LGD,PD) $=30 \%$ & rho(LGD,PD) $=50 \%$ \\
\hline Effective Capital Buffer (\%) - Asset-Weighted Average & $10.7 \%$ & $10.3 \%$ & $0.4 \%$ & $0.4 \%$ \\
\hline Effective Capital Buffer (\%) - Median & $11.1 \%$ & $10.8 \%$ & $0.4 \%$ & $0.4 \%$ \\
\hline Effective Capital Buffer (\%) - St.Dev. & $2.9 \%$ & $3.1 \%$ & $4.8 \%$ & $4.7 \%$ \\
\hline Effective Undercapitalization (\% of Profits) & $7 \%$ & $14 \%$ & $128 \%$ & $129 \%$ \\
\hline \# of Banks with Effective Capital Buffer $<8 \%$ & 1 & 2 & 9 & 9 \\
\hline \multirow[t]{2}{*}{ \# of Banks with Effective Capital Buffer $<2 \%$} & 0 & 0 & 6 & 6 \\
\hline & c_cap $=99.5$ & c_cap $=99.9$ & c_cap $=99.5$ & c_cap $=99.9$ \\
\hline Effective Capital Buffer (\%) - Asset-Weighted Average & $10.3 \%$ & $7.2 \%$ & $0.4 \%$ & $0.2 \%$ \\
\hline Effective Capital Buffer (\%) - Median & $10.8 \%$ & $7.6 \%$ & $0.4 \%$ & $0.3 \%$ \\
\hline Effective Capital Buffer (\%) - St.Dev. & $3.1 \%$ & $1.9 \%$ & $4.7 \%$ & $3.3 \%$ \\
\hline Effective Undercapitalization (\% of Profits) & $14 \%$ & $79 \%$ & $129 \%$ & $167 \%$ \\
\hline \# of Banks with Effective Capital Buffer $<8 \%$ & 2 & 6 & 9 & 10 \\
\hline \multirow[t]{2}{*}{ \# of Banks with Effective Capital Buffer $<2 \%$} & 0 & 0 & 6 & 8 \\
\hline & corp.hedging $=50 \%$ & corp.hedging $=30 \%$ & corp.hedging $=50 \%$ & corp.hedging $=30 \%$ \\
\hline Effective Capital Buffer (\%) - Asset-Weighted Average & $10.3 \%$ & $10.3 \%$ & $0.4 \%$ & $0.0 \%$ \\
\hline Effective Capital Buffer (\%) - Median & $10.8 \%$ & $10.8 \%$ & $0.4 \%$ & $0.0 \%$ \\
\hline Effective Capital Buffer (\%) - St.Dev. & $3.1 \%$ & $3.1 \%$ & $4.7 \%$ & $4.7 \%$ \\
\hline Effective Undercapitalization (\% of Profits) & $14 \%$ & $14 \%$ & $129 \%$ & $145 \%$ \\
\hline \# of Banks with Effective Capital Buffer $<8 \%$ & 2 & 2 & 9 & 9 \\
\hline \# of Banks with Effective Capital Buffer $<2 \%$ & 0 & 0 & 6 & 8 \\
\hline
\end{tabular}

Notes: Author's calculations.

reporting framework for banks is in place in the country that is analysed, that this framework is adequate and reliable enough to be used for stress testing purposes, and that it is comparable to current international standards. In more advanced countries, prudential regulation authorities would have implemented the International Financial Reporting Standards (IFRS) ${ }^{46}$ Additionally, in some countries (e.g. Bulgaria, Turkey and others)

\footnotetext{
${ }^{46}$ Although specific national accounting standards are still used by banks in some Eastern European countries, others have already implemented IFRS. Note that the US Generally Accepted Accounting Principles (GAAP) is envisaged to converge to IFRS or be replaced by IFRS in the near future.
} 
bank-by-bank data on credit exposures within selected asset classes are published by the supervisory authority as part of the Pillar 3 information disclosure of Basel II.

In any case, banks should be obliged to publish their external audit reports that would, under normal circumstances, include most of the information needed to deploy the proposed stress testing approach at a reasonable level of granularity and with the necessary bank-by-bank information. For instance, based on prevailing accounting standards (including the IFRS), audit reports normally have a classification of lending to individual borrowers, companies, other financial institutions, and the state and state owned enterprises (SOEs). This would make it possible to differentiate across the banks with regards to the structure of their credit exposures. In addition, the level of secured loans and collateral can be obtained and applied (correspondingly or judgmentally) to classify credit exposures by their level of security and their associated LGDs.

Overall loan exposures or exposures in selected asset classes can be constructed from historical audit reports. The most recent credit growth period can be determined from aggregate historical data published by the central bank or the supervisor. Credit growth at the individual bank level in the period of interest and in selected asset classes can be determined based on the year-to-year change in credit exposures published in external audit reports, and then used to compute the individual PDs based on the scaling factor that is proposed in Section 4.6. Indirect credit risks from FX exposures can also be estimated based on data from audit reports. If no data at the asset class level is available, this information should be available at least at the individual bank level and can be incorporated into the proposed framework as outlined in the paragraph following Equation (6). General as well as specific provisions or loan loss reserves and Tier 1 and Tier 2 capital can also be obtained from the audit reports. 
Similarly, a bank level approximation of off-balance sheet exposures can be taken from the audit reports and added (either proportionately or judgmentally) to the individual onbalance sheet exposures. Lending concentration and residual maturity can be aggregated at the bank level if no asset class data are available or skipped altogether if relevant data are not retrievable. With this information, the minimal set of bank-level variables can be compiled so that the proposed approach can be deployed at a reasonable degree of granularity, where it is assumed that the required (country-specific) macroeconomic data are available either from country authorities or IFIs.

\section{Conclusion}

This paper proposed a macroprudential stress testing approach and illustrated its application and properties on an empirical data for a set of Eastern European banks. The innovative features of the proposed macroprudential stress tests were inspired by the effects of the global financial crisis on Eastern Europe. We demonstrated in the empirical application section how the proposed approach can be effectively used to identify systemic and idiosyncratic risk factors to gauge the relative financial soundness and resilience of individual banks to economic risks. The proposed approach is also useful for monitoring and assessing banking-sector wide systemic risks via aggregate measures of outcome indicators under the three different macroeconomic scenarios that are analysed.

The direction of future research should focus on estimating the response functions of the banking sector and the policy makers to changing balance-sheet solvency conditions of the banking system. Future research should also focus on connecting these response functions to the real economy so that dynamic stress tests can be constructed which would enable stress testers to study the response pattern of some key macroeconomic and 
bank specific variables to various shocks that hit the economy and the financial system. Nonetheless, it is important to highlight here that bank-level granularity, which is valuable to policy makers, should be preserved to ensure the practical usefulness of any newly proposed approaches relative to pure macroeconomic models which contain an aggregate financial sector. 


\section{References}

Altman, Edward I., Andrea Resti and Andrea Sironi (2002): "The link between default and recovery rates: effects on the procyclicality of regulatory capital ratios," BIS Working Paper No. 113, Bank for International Settlements.

Alves, I. (2004): “Corporate fragilitys sectoral dynamics and determinants: evidence from expected default measures," mimeo, European Central Bank.

Arellano, Manuel and Stephen Bond (1991): "Some Tests of Specification for Panel Data: Monte Carlo Evidence and an Application to Employment Equations," Review of Economic Studies, 58(2), 277-297.

Bangia, Anil, Francis X. Diebold, Andre Kronimus, Christian Schagen and Til Schuermann (2002): "Ratings migration and the business cycle, with application to credit portfolio stress testing," Journal of Banking and Finance, 26(2-3), 445-474.

Basel II (2006): "International Convergence of Capital Measurement and Capital Standards: A Revised Framework - Comprehensive Version," Bank for International Settlements. Available from: http: //www.bis.org/publ/bcbs128.pdf.

Basurto, Miguel A. Segoviano and Charles A. E. Goodhart (2009): “Banking Stability Measures," IMF Working Paper No. 09/4, International Monetary Fund.

BIS (2006): "Results of the fifth quantitative impact study (QIS 5)," Bank for International Settlements. Available from: http:/ / www.bis.org/bcbs/qis/qis5results.pdf.

(2010): "Basel III: A global regulatory framework for more resilient banks and banking systems," Bank for International Settlements. Available from: http:/ /www.bis.org/publ/bcbs189.pdf.

Bluhm, Christian, Ludger Overbeck and Christoph Wagner (2003): An Introduction to Credit Risk Modeling, Chapman and Hall.

Brand, Claus, Daniel Buncic and Jarkko Turunen (2010): “The Impact of ECB Monetary Policy Decisions and Communication on the Yield Curve," Journal of the European Economic Association, 8(6), 1266-1298.

Breuer, Thomas, Martin Jandacka, Klaus Rheinberger and Martin Summer (2009): "How to find plausible, severe, and useful stress scenarios," International Journal of Central Banking, 5(3), 205224.

Buncic, Daniel (2011): "Understanding forecast failure of ESTAR models of real exchange rates," Empirical Economics, in Press. Available from: http:/ / www.springerlink.com/content/ 5k42q75364q86561/fulltext.pdf.

Buncic, Daniel and Martin Melecky (2008): “An Estimated New Keynesian Policy Model for Australia," The Economic Record, 84(264), 1-16. 
Christiano, Lawrence, Roberto Motto and Massimo Rostagno (2010): "Financial factors in economic fluctuations," ECB Working Paper No. 1192, European Central Bank.

Čihák, Martin (2007): “Introduction to Applied Stress Testing," IMF Working Paper No. 07/59, International Monetary Fund.

Čihák, Martin and Klaus Schaeck (2010): "How well do aggregate prudential ratios identify banking system problems?" Journal of Financial Stability, 6(3), 130-144.

de Larosiére, Jacques (2009): “The high-level group on financial supervision in the EU," EU Report on Supervision. Available from: http://ec.europa.eu/internal_market/finances/docs/ de_larosiere_report_en.pdf.

De Nicolo, Gianni and Marcella Lucchetta (2010): "Systemic Real and Financial Risks: Measurement, Forecasting and Stress Testing," IMF Jacques Polak Research Conference. Washington, D.C., International Monetary Fund.

Drehmann, Mathias and Mark Manning (2004): "Systemic factors influencing UK equity returns," mimeo, Bank of England.

Foglia, Antonella (2009): “Stress Testing Credit Risk: A Survey of Authorities' Aproaches," International Journal of Central Banking, 5(3), 9-45.

Galati, Gabriele and Richhild Moessner (2011): "Macroprudential policy - A literature review," BIS Working Papers No. 337, Bank for International Settlements.

Glick, Reuven and Michael M. Hutchison (1999): “Banking and Currency Crises: How Common Are Twins?" Working Paper No. PB99-07, Federal Reserve Bank of San Francisco. Available from: http:/ /ideas.repec.org/p/kud/epruwp/99-20.html.

Haldane, Andrew G. (2009): "Why banks failed the stress test," Speech given at the Marcus-Evans Conference on Stress-Testing. Available from: http: / www.bankofengland.co.uk/publications / speeches/2009/speech374.pdf.

Ivanov, Ventzislav and Lutz Kilian (2005): “A Practitioner's Guide to Lag Order Selection For VAR Impulse Response Analysis," Studies in Nonlinear Dynamics \& Econometrics, 9(1), Article 2.

Kaminsky, Graciela L. and Carmen M. Reinhart (1999): “The Twin Crises: The Causes of Banking and Balance-of-Payments Problems," American Economic Review, 89(3), 473-500.

Kumhof, Michael, Dirk Muir, Susanna Mursula and Douglas Laxton (2010): "The Global Integrated Monetary and Fiscal Model (GIMF) Theoretical Structure," IMF Working Paper No. 10/34, International Monetary Fund.

Laeven, Luc and Fabian Valencia (2008): "Systemic Banking Crises: A New Database," IMF Working Papers No. 08/224, International Monetary Fund.

Lütkepohl, Helmut (2005): New introduction to multiple time series analysis, Springer Verlag, Berlin. 
Melecky, Martin and Anca Maria Podpiera (2010): "Macroprudential stress-testing practices of central banks in central and south eastern Europe : an overview and challenges ahead," Policy Research Working Paper Series No. 5434, The World Bank.

Moody's (2010): “Corporate Default and Recovery Rates, 1920-2009," Moody's Global Credit Research.

OeNB (2010): "Financial Stability Report 19," Austrian National Bank, Vienna, June 2010.

Papke, Leslie E. and Jeffrey M. Wooldridge (2008): "Panel data methods for fractional response variables with an application to test pass rates," Journal of Econometrics, 145(1-2), 121-133.

Pesaran, M. Hashem, Til Schuermann, Bjorn-Jakob Treutler and Scott M. Weiner (2006): “Macroeconomic Dynamics and Credit Risk: A Global Perspective," Journal of Money, Credit and Banking, 38(5), 1211-1261.

Peura, Samu and Esa Jokivuolle (2004): "Simulation based stress tests of banks' regulatory capital adequacy," Journal of Banking and Finance, 28(8), 1801-1824.

Reinhart, Carmen M. and Kenneth S. Rogoff (2004): “The Modern History of Exchange Rate Arrangements: A Reinterpretation," The Quarterly Journal of Economics, 119(1), 1-48.

Sargan, Dennis J. (1958): “The estimation of economic relationships using instrumental variables," Econometrica, 26(3), 393-415.

Schmieder, Christian, Claus Puhr and Maher Hasan (2011): “Next Generation Balance Sheet Stress Testing," IMF Working Paper No. 11/83, International Monetary Fund.

Sorge, Marco (2004): "Stress testing Financial Systems: an overview of current methodologies," BIS Working Papers No. 165, Bank for International Settlements.

Swinburne, Mark (2007): "The IMFs Experience with Macro stress-testing," Paper presented at ECB High level conference on simulating financial instability, Frankfurt am Main. Available from: http:/ / www.ecb.int/events/pdf/conferences/sfi/Swinburne.pdf.

Turner (2009): "The Turner Review: A regulatory response to the global banking crisis," Financial Services Authority Report. Available from: http://www.fsa.gov.uk/pubs/other/turner_review. pdf.

Virolainen, Kimmo (2004): "Macro stress testing with a macroeconomic credit risk model for Finland," Research Discussion Papers No. 2004/8, Bank of Finland.

Wälti, Sébastien (2005): “The duration of fixed exchange rate regimes," Discussion Paper No. 96, The Institute for International Integration Studies. Available from: http://ideas.repec.org/p/ iis/dispap/iiisdp96.html.

World Bank (2008): "The Unfolding Crisis: Implications for Financial Systems and their Oversight," Financial Systems and Development Economics Department. Available from: http://www. worldbank.org/financialcrisis/pdf/UnfoldingCrisis.pdf. 